\title{
Loop-Mediated Isothermal Amplification and Polymerase Chain Reaction Methods for Specific and Rapid Detection of Rhodococcus fascians
}

\author{
M. Serdani, M. Curtis, M. L. Miller, J. Kraus*, and M. L. Putnam, Department of Botany and Plant Pathology, Oregon State \\ University, Corvallis, OR 97331
}

\begin{abstract}
Serdani, M., Curtis, M., Miller, M. L., Kraus, J., and Putnam, M. L. 2013. Loop-mediated isothermal amplification and polymerase chain reaction methods for specific and rapid detection of Rhodococcus fascians. Plant Dis. 97:517-529.

Rhodococcus fascians is a phytopathogenic actinobacterium which causes leafy galls and other plant distortions that result in economically significant losses to nurseries producing ornamental plants. Traditional assays for detection and identification are time-consuming and laborious. We developed a rapid polymerase chain reaction (PCR) diagnostic assay based on two primer pairs, p450 and fas, which target the fas $A$ and fas $D$ genes, respectively, that are essential for pathogenicity. We also developed a faster, more convenient, loop-mediated isothermal amplification (LAMP) assay targeting the fas $R$ gene, which regulates expression of virulence genes. Both assays were evaluated for sensitivity and specificity in vitro and in planta. The p450 and fas primers amplified DNA only from pure cultures of pathogenic reference isolates of $R$. fascians. Nonpathogenic isolates and 51 other plantassociated bacteria were not amplified. The PCR primers correctly

isolated from naturally infected plants. The PCR assay correctly discriminated between pathogenic $R$. fascians and other bacteria in 132 of $139(95 \%)$ naturally infected plants, and in 34 of $34(100 \%)$ artificially inoculated plants. The fas primers were slightly more accurate than the p450 primers. The LAMP assay accurately detected pathogenic $R$. fascians in 26 of 28 (93\%) naturally infected plants and did not react with 23 asymptomatic plants. The LAMP primers also amplified product for DNA extracts of 40 of 41 bacterial strains isolated from plants with leafy galls. The detection limit of both the PCR and LAMP assays was approximately $10^{3} \mathrm{CFU} / 30-\mu \mathrm{l}$ reaction. These new tools allow fast, reliable, and accurate detection of $R$. fascians in vitro and in planta. The LAMP assay in particular is a significant advancement in rapid $R$. fascians diagnostics, and enables those with limited laboratory facilities to confirm the presence of this pathogen in infected plants.
\end{abstract} detected pathogenic $R$. fascians from 73 of 75 (97\%) bacterial strains
The actinobacterium Rhodococcus fascians (Tilford) Goodfellow causes plant malformations such as leafy galls, witches'brooms, shoot proliferation, adventitious growth, and distortion of underground storage tissues such as bulbs (24). R. fascians is a member of the family Nocardiaceae (suborder Corynebacterineae), and as such is Gram positive, does not form spores, and is variable in cellular morphology (nocardioform). This species is a pathogen of over 100 genera of primarily herbaceous hosts $(19,24)$, most of which are grown as ornamentals. Cytokinins produced by the bacteria stimulate growth of dormant plant meristems, and cortical cells are reprogrammed to grow as new meristematic tissues (16). The combined effects of these hormonal perturbations are the formation of multiple shoot primordia, growth of adventitious tissues, leafy galls, and shoot proliferation, all of which disfigure plants grown specifically for their aesthetic appeal. Wholesale production nurseries have experienced significant financial losses due to either the cost of destroying diseased material and lost production time (24) or to implementing extraordinary disease-prevention tactics (e.g., installing filtration systems to purify irrigation water and disinfecting structures). $R$. fascians losses at one nursery were estimated at $\$ 150,000$ over a 5-year period, and this is from a nursery with the most stringent phytosanitary standards. The pathogen lives as an epiphyte prior to tissue ingress and initiation of symptoms $(3,11)$. Symptom expression may therefore be delayed for up to 6 months (12), which creates a difficult

Corresponding author: M. L. Putnam,

E-mail: putnamm@science.oregonstate.edu

*Deceased.

Accepted for publication 7 November 2012.

http://dx.doi.org/10.1094/PDIS-02-12-0214-RE

(C) 2013 The American Phytopathological Society situation for growers who may be unknowingly maintaining infected plants.

Diagnosis of $R$. fascians is complicated by the similarity of its symptoms to other infectious agents, such as phytoplasmas, eriophyid mites, and other bacteria $(11,24,26)$. In very young plants propagated from cuttings or tissue culture, the crown gall bacterium Agrobacterium tumefaciens can, in some hosts, cause stunted shoots, which emerge from enlarged masses of tissues, somewhat resembling a leafy gall. Additionally, symptoms produced by $R$. fascians can look very much like those produced by plant-growth regulators, which are used routinely in the industry to produce bushy, compact plants with good color that will not outgrow their pots prior to sale.

Our focus on $R$. fascians detection started in 2002, after the Oregon State University Plant Clinic received a request to test large numbers of plants for A. tumefaciens; however, the symptoms were clearly those of $R$. fascians. Traditionally, detection of $R$. fascians has been a difficult and time-consuming process. The pathogen grows slowly on nutrient media and may be quickly overgrown by other microflora. Isolation, purification, and confirmation by biochemical tests can take up to 4 weeks. Nonpathogenic forms of $R$. fascians are often present $(13,24,35)$, and positive identification of such forms necessitates methods that can distinguish them from pathogenic strains. Inoculation to indicator hosts is the standard method to confirm pathogenicity, but this can take 2 to 4 weeks, the time required for unequivocal symptom development. To remedy this situation, we developed a rapid, specific, and sensitive polymerase chain reaction (PCR) assay for detection of the pathogen in planta.

Pathogenicity genes have been exploited in studies examining virulence $(3-5,15,16,28,29)$, and may have utility for diagnostics. Pathogenicity genes are present at three different loci (fas, att, and hyp) on a linear conjugative plasmid, pFiD188 (4,5). The fasciation (fas) operon contains genes necessary for cytokinin biosynthesis, the products of which are essential for pathogenicity and symptom expression; inactivation of the attenuation (att) locus results in 
reduced or attenuated leafy galls; whereas inactivation of one gene in the hypervirulent (hyp) locus results in increased virulence $(4,15)$. The fas $D$ region (a.k.a. fas- 1 ) encodes an isopentenyltransferase and was the target for PCR primers developed to determine whether there was a consistent association of the presence of the gene with pathogenicity (27). While our work was in progress, PCR primers for eight gene regions, including fasD, were developed to characterize $R$. fascians virulence (21). However, none of these primers were tested in planta, nor were they evaluated as diagnostic tools.

In 2000, a novel means of highly specific DNA amplification, loop-mediated isothermal amplification (LAMP), was described (22). LAMP has been successfully applied to the rapid detection (within an hour) of numerous microbial pathogens, including phytopathogens $(9,10,25,30,31,33,34)$. The reaction uses four to six primers, which simultaneously target six to eight nucleotide sequences, thereby enhancing specificity by minimizing nonspecific binding. The Bst polymerase used in the reaction has strand-displacement activity, thereby permitting target amplification at a constant temperature (e.g., 60 to $64^{\circ} \mathrm{C}$ ). This eliminates the need for high-precision thermal cyclers and gel electrophoresis. DNA may be detected by addition of a double-stranded DNA-binding fluorochrome (e.g., PicoGreen) to the product or simply by visual evaluation (10) of the white precipitate by-product of amplification, magnesium pyrophosphate, which can also be quantified using a turbidimeter.

After years of diagnosing $R$. fascians-infected plants, it seemed that a LAMP assay would accommodate growers at wholesale nurseries who wanted their own means to assay suspect plants without the costs of purchasing specialized laboratory equipment. This paper describes the development and verification of PCR and LAMP assays for the detection of pathogenic $R$. fascians, and presents comparisons of their relative efficacy for diagnosing infection in planta.

\section{Materials and Methods}

Bacterial cultures and culture conditions. Plant-associated bacterial strains were either retrieved from freezer storage or collected as described below. $R$. fascians strains were maintained on Miller medium (MrM) consisting, in g/liter, of mannitol (10), casein (4), peptone (4), $\mathrm{NH}_{4} \mathrm{Cl}$ (1), yeast extract (3), $\mathrm{MgSO}_{4} \cdot 7 \mathrm{H}_{2} \mathrm{O}$ (0.3), $\mathrm{NaCl}(0.2)$, and $\mathrm{KH}_{2} \mathrm{PO}_{4}(0.5)$. The $\mathrm{pH}$ of the medium was adjusted to 6.5 , and $15 \mathrm{~g}$ of agar was added prior to autoclaving for $20 \mathrm{~min}$ at $103.4 \mathrm{kPa}$. The sterile medium was cooled to $50^{\circ} \mathrm{C}$, then $10 \mathrm{ml}$ of sterile $2 \%$ cycloheximide (wt/vol) was added and mixed prior to pouring into petri dishes. Isolates were maintained in longterm storage at $-80^{\circ} \mathrm{C}$ in Luria broth and $20 \%$ glycerol.

Isolation and identification of new bacterial strains. Plants with leafy galls, shoot proliferation, distortion, or other symptoms suggestive of infection by $R$. fascians, which were previously submitted to the Oregon State University Plant Clinic for diagnosis, were used for isolations. The isolates reported here were obtained from plant material submitted between 2002 and 2011. A sample of affected tissues was rinsed briefly with tap water to remove visible soil particles. Small pieces ( 3 to $5 \mathrm{~mm}$ in length) of symptomatic tissue were placed into each of two tubes containing $3 \mathrm{ml}$ sterile $0.85 \%$ saline and $2 \%$ (wt/vol) cycloheximide, and incubated for 30 to $120 \mathrm{~min}$ at room temperature $\left(21\right.$ to $\left.23^{\circ} \mathrm{C}\right)$. The saline suspension was then streaked to plates of the semi-selective medium D2 (7) and incubated at 21 to $23^{\circ} \mathrm{C}$. Plates were examined after 5 to 10 days. Domed, moist-looking, small, chrome-yellow colonies were selected, individually suspended in $3 \mathrm{ml}$ of sterile deionized water (SDW), and streaked to MrM. Individual colonies were selected and re-streaked a minimum of three times or until apparently pure cultures were obtained, as determined by colony appearance and examination of stained bacterial smears at $\times 1,000$.

All purified strains recovered from symptomatic plants were initially identified by colony morphology on D2, a positive Gram reaction, production of urease (14), and morphology at $\times 1,000$ of 24-h cells grown at $27^{\circ} \mathrm{C}$ on tryptic soy agar. Individual cells of $R$. fascians are small rods, $0.5-0.9 \times 1.5-4 \mu \mathrm{m}$, and are generally straight, but may be slightly clubbed at one end. Further identification was made by one or more of the following methods: substrate utilization using a commercially available system according to the manufacturer's directions (Biolog, version ML2, Biolog Inc., Hayward, CA); sequencing of a portion of the $16 \mathrm{~S}$ rRNA gene; or assaying for virulence by inoculation to indicator plants.

Pathogenicity testing. Sweet pea (Lathyrus odoratus) or garden pea (Pisum sativum) have traditionally been used to determine virulence of $R$. fascians $(11,12,20,32)$. To determine which species and cultivars were most suitable for assays, we used four pathogenic isolates of $R$. fascians to separately inoculate three cultivars of sweet pea (Elegance, Mrs. Collier, and Multiflora) and three of garden pea (Laxton Progress \#9, Oregon Sugar Pod II, and Tall Telephone). Ten seeds of each cultivar were surface sterilized by first washing in running tap water for $1 \mathrm{~h}$, then immersing in a $0.6 \% \mathrm{NaOCl}$ solution for $15 \mathrm{~min}$. The seeds were rinsed with SDW and placed onto moist, sterilized filter papers in sterile petri dishes to germinate. After germination, the seedlings were soaked in approximately $40 \mathrm{ml}$ of a $10^{8} \mathrm{CFU} / \mathrm{ml}$ suspension for $2 \mathrm{~h}$. All seeds of one cultivar were then planted into a 1-gal pot containing a commercial peat-based potting mix (Sunshine SB 40, Sun Gro Horticulture Canada Ltd.) and incubated in the greenhouse at ambient temperature and light, supplemented with 16-h photoperiod (400 $\mathrm{W}$ sodium vapor lamps suspended $4 \mathrm{ft}$ above the bench). Controls included peas inoculated with the nonpathogenic $R$. fascians isolate 02-416 and noninoculated seeds, which were immersed in water. Garden pea cv. Tall Telephone was less consistent in symptom expression at 4 weeks (data not shown) and so was not used further. Sweet pea seeds have a much thicker seed coat, take longer to germinate, and are more expensive than garden pea, so garden pea cvs. Laxton Progress \#9 and Oregon Sugar Pod II were used for pathogenicity tests from 2002 through 2004.

Evening primrose, Oenothera speciosa 'Siskiyou', was also used as an indicator host, as it was more representative of plant samples from nurseries (24). For inoculations, $R$. fascians strains were grown for 2 to 3 days on $\mathrm{MrM}$, and an aqueous suspension was adjusted to $10^{8} \mathrm{CFU} / \mathrm{ml}$ (Klett colorimeter [clinical model, Scienceware, Pequannock, NJ] reading of 230 at $590 \mathrm{~nm}$ [blue filter]). For virulence testing, four plants in 4-in. pots were drenched with $25 \mathrm{ml}$ of the suspension. Plants treated with the pathogenic strain A44a or water were used as positive and negative controls, respectively. Inoculated plants were covered with clear plastic bags to provide a moist environment for 2 weeks, after which the plants were evaluated for symptoms.

PCR detection of $\boldsymbol{R}$. fascians. DNA template for PCR was prepared from either single bacterial colonies or symptomatic plant tissue. Bacterial strains were grown on MrM for 2 days, and an inoculating loopful of bacteria was suspended in $750 \mu \mathrm{l}$ of molecular grade water $(\mathrm{MGW})$ in a microfuge tube. Bacterial genomic DNA was then extracted using InstaGene matrix (Bio-Rad, Hercules, CA). Alternatively, template DNA was prepared by simple heat lysis of the cells. A sterile 10- $\mu$ l pipette tip was touched to a single colony of bacteria, the cells were dislodged into $1.5 \mathrm{ml} \mathrm{MGW}$, and heated at $100^{\circ} \mathrm{C}$ for $8 \mathrm{~min}$. Both methods provided amplifiable DNA.

Two approaches were evaluated for detecting $R$. fascians on inoculated, symptomatic plant tissues: plant washes and tissue extracts. Plants were inoculated with known strains of $R$. fascians to confirm each method. The plant wash method involved incubating diseased tissue in a solution prior to assaying the liquid. Leafy galls initiated by $R$. fascians were aseptically removed from infected plants, lightly rinsed with tap water, and cut into pieces from 3 to $5 \mathrm{~mm}$ in length. Two pieces were placed into each of two tubes of $3 \mathrm{ml}$ sterile $0.85 \%$ saline containing $2 \%$ (wt/vol) cycloheximide. After 1 to 3 days incubation at room temperature $\left(21\right.$ to $\left.23^{\circ} \mathrm{C}\right)$, the plant tissue was discarded from each tube and $1.4 \mathrm{ml}$ of the incubation liquid was transferred to a 2-ml microfuge tube, to which 200 $\mu \mathrm{l}$ of InstaGene matrix was added for DNA extraction.

For the tissue extract method, the incubation step was omitted and DNA was extracted directly from symptomatic plant tissue. 
Affected tissues were rinsed free of surface debris, and two subsamples of 100 to $200 \mathrm{mg}$ each were homogenized using a FastPrep-24 (MP Biomedicals, Inc.) instrument for $40 \mathrm{~s}$ at a speed setting of 6.0. Total genomic DNA was isolated using a Fast DNA Spin Kit (MP Biomedicals, Inc.). To perform quality control checks on template preparations, "universal" primers (23) (Table 1) were used to amplify a 1,500-bp fragment of the bacterial $16 \mathrm{~S}$ rRNA.

Primers for detecting $R$. fascians DNA were designed to target conserved regions of either the fasA (p450 primer set) or fasD (fas primer set) genes (GenBank Z29635; Table 1). A Basic Local Alignment Search Tool (BLAST) (1) analysis with each primer pair confirmed that only the $R$. fascians $\mathrm{P} 450$ monooxygenase or the isopentenyltransferase genes share sequence identity with both the forward and reverse primers of the p450 and fas pair, respectively.

PCR conditions were optimized by varying the annealing temperature, extension time, and amount of template used. One microliter of undiluted template DNA from plant washes, tissue extracts, or single bacterial colonies was used in $30 \mu \mathrm{l}$ (total volume) of a PCR mix consisting of $22.8 \mu \mathrm{l}$ of molecular grade water, $3.0 \mu \mathrm{l}$ of $10 \times \mathrm{Taq}$ buffer, $0.9 \mu \mathrm{l}$ of $50 \mathrm{mM} \mathrm{MgCl}{ }_{2}, 0.6 \mu \mathrm{l}$ of a $10 \mathrm{mM}$ mix of each dNTP, $0.6 \mu \mathrm{l}$ of each primer $(50 \mu \mathrm{M}), 0.9 \mu \mathrm{l}$ of a $1.2 \%$ bovine serum albumin solution, and $0.2 \mu \mathrm{l}$ of $5 \mathrm{U} / \mu \mathrm{l} \mathrm{Taq}$ DNA polymerase (Invitrogen Corporation, Carlsbad, CA). We used an MJ Research PTC 200 thermal cycler and a cycling profile of $94^{\circ} \mathrm{C}$ for $2 \mathrm{~min}$ followed by 33 cycles of $94^{\circ} \mathrm{C}$ for $30 \mathrm{~s}, 55^{\circ} \mathrm{C}$ for $30 \mathrm{~s}$, and $72^{\circ} \mathrm{C}$ for $1 \mathrm{~min}$. Ten microliters of product was then electrophoresed in $1.5 \%$ agarose gel at $100 \mathrm{~V}$ for 60 to $90 \mathrm{~min}$ and photographed after ethidium bromide staining. All sample assays included a nontemplate (MGW) control and DNA extracts of the known pathogenic strain A44a.

Primer specificity was tested using 51 strains of plant-associated bacteria and seven pathogenic and nonpathogenic $R$. fascians strains (Table 2). Template DNA was prepared by heat lysis as described above. From all 58 bacterial extracts, we observed a 1,500-bp amplicon with nonspecific $16 \mathrm{~S}$ rRNA primers, indicating sufficient template DNA in the preparations. Sensitivity of the PCR primers was determined using a serial dilution of 2-day cultures of strain A44a added to plant tissues. Petunia (Petunia $\times$ hybrida) and evening primrose, two ornamentals commonly infected by $R$. fascians and useful as indicator hosts (17), were used to simulate naturally infected material and to assess whether PCR (or LAMP, below) is inhibited by plant extracts. One milliliter of a 10-fold serial dilution $\left(10^{-1}\right.$ to $\left.10^{-8}\right)$ of each bacterial suspension was centrifuged at 6,000 rpm (Microfuge18 Centrifuge, Beckman Coulter) for 10 min, and $900 \mu \mathrm{l}$ of supernatant was removed and discarded. The remaining $100 \mu \mathrm{l}$ of resuspended cells for each dilution were added to $100 \mathrm{mg}$ of leaf tissue, and total DNA was isolated using a Fast DNA Spin Kit. One microliter of the extract for each dilution was used as template in each of three assays. The concentrations of the dilutions were determined by triplicate plating $100 \mu \mathrm{l}$ of the three most dilute cell suspensions onto MrM, and counting colonies after 2 days at $27^{\circ} \mathrm{C}$.

A preliminary assay of the ability of our PCR primers to detect $R$. fascians in infected tissue was performed. Eight different pathogenic strains of $R$. fascians were inoculated to one or more cultivars of susceptible plants in duplicate. Plants used were $O$. speciosa 'Siskiyou'; Campanula 'Sarastro'; Erysimum 'Apricot Twist', 'Bowles Mauve', and 'Variagata'; Veronica 'Blue Fox'; Tiarella sp.; and Iberis gilbraltarica. A total of 34 plants were inoculated. Samples of symptomatic tissue were collected and suspended in sterile saline as described above (plant wash method), prior to DNA extraction and amplification. Samples were assayed using the $R$. fascians-specific $\mathrm{p} 450$ and fas primers, and the "universal" $16 \mathrm{~S}$ primer set in separate PCR reactions.

The ability of the p450 and fas primers to detect $R$. fascians in naturally infected plants was determined by use on both symptomatic and asymptomatic Plant Clinic samples with either the plant wash method (samples received 2002 to 2007) or the tissue extract method (samples received 2008 to 2011; Table 3). Pathogenicity of a subset of the bacterial strains recovered from plants was determined by inoculation to garden pea (samples received prior to 2005 ) or evening primrose (samples received after 2005). For samples with no amplification, an aliquot of tissue extract was diluted 1:10 with MGW and re-assayed. Extracts of Coreopsis, Echinacea, Erodium, Gaillardia, Heuchera, Lamium, Lavatera, Leucanthemum, Physocarpus, and Rosa often required dilution.

LAMP detection of $\boldsymbol{R}$. fascians. Inner (FIP, BIP) and outer (F3, B3) primers specific to regions of the fas $R$ gene, an AraC-type regulator, which regulates transcription of the fas operon (29), were designed using PrimerExplorer V3 software (Eiken Co., Ltd., Japan). Out of the 20 primer sets evaluated, one set, number p16, was selected for further analysis; two optional loop-primers (FLoop and B-Loop; 18) were designed in addition to the inner and outer primers (Table 1). DNA template for LAMP was prepared either from single bacterial colonies using heat lysis or from symptomatic plant tissue by homogenization (FastPrep-24, followed by Fast DNA Spin Kit, as described above). The standard LAMP reaction was performed in a $30 \mu$ (total volume) reaction mixture containing $14.9 \mu \mathrm{l} \mathrm{MGW,} 3 \mu \mathrm{l} 10 \times$ Bst buffer, $1.2 \mu \mathrm{l}(100$ $\mathrm{mM}) \mathrm{MgSO}_{4}, 2.4 \mu \mathrm{l}(5 \mathrm{M})$ betaine (Sigma-Aldrich Corp, St. Louis, MO), $3 \mu \mathrm{l}(10 \mathrm{mM})$ mix of each dNTPs, $0.35 \mu \mathrm{l}(100 \mu \mathrm{M})$ each primers FIP and BIP, $0.3 \mu \mathrm{l}(10 \mu \mathrm{M})$ each primers F3 and B3, 1.2 $\mu \mathrm{l}(8 \mathrm{U} / \mu \mathrm{l})$ Bst polymerase (New England Biolabs), and $3 \mu \mathrm{l}$ template DNA. The reactions, in clear, $0.2-\mathrm{ml} \mathrm{PCR}$ tubes, were incubated for $50 \mathrm{~min}$ in a water bath at $64^{\circ} \mathrm{C}$. Immediately after, reactions were centrifuged $10 \mathrm{~s}$ at $6,000 \mathrm{rpm}$, visually inspected for a white pellet, and $10 \mu \mathrm{l}$ of the reaction mixture was removed and added to $2 \mu \mathrm{l}$ PicoGreen in a microfuge tube. A yellow color and

Table 1. Primers used in the course of this study

\begin{tabular}{|c|c|c|c|c|}
\hline Primer name & Primer sequence $\left(5^{\prime}\right.$ to $\left.3^{\prime}\right)$ & Primer target & Product size (bp) & Reference \\
\hline $\begin{array}{l}16 \mathrm{~S}-\mathrm{F} \\
16 \mathrm{~S}-\mathrm{R}\end{array}$ & $\begin{array}{l}\text { AGAGTTTGATCMTGGCTCAG } \\
\text { TACGGYTACCTTGTTACGACTT }\end{array}$ & $16 \mathrm{~S}$ ribosomal DNA & 1,500 & (23) \\
\hline $\begin{array}{l}\mathrm{p} 450-\mathrm{F} \\
\mathrm{p} 450-\mathrm{R}\end{array}$ & $\begin{array}{l}\text { TATCCTTGCTGCGGAGTTCT } \\
\text { CAACCACCGCAATAATTCCT }\end{array}$ & $\begin{array}{l}\text { fas } A, \\
\text { P450 monooxygenase }\end{array}$ & 538 & $\begin{array}{l}\text { This paper, } \\
\text { (5) }\end{array}$ \\
\hline $\begin{array}{l}\text { fas-F } \\
\text { fas- } R\end{array}$ & $\begin{array}{l}\text { CAACACTACTTTGCCCAGCA } \\
\text { GGCCAACTCCTCTGGTGTTA }\end{array}$ & $\begin{array}{l}\text { fas } D, \\
\text { isopentenyltransferase }\end{array}$ & 195 & $\begin{array}{l}\text { This paper, } \\
\text { (5) }\end{array}$ \\
\hline $16 \mathrm{~F} 3$ & ACTCGTCGACAGGTTGATCT & fas $R$, & 191 & This paper \\
\hline $16 \mathrm{~B} 3$ & GTGACTACCGCTAAACAGCT & AraC-type regulator & & \\
\hline 16FIP & $\begin{array}{l}\text { TGCGACAGAATTACTTCGCCC } \\
\text { GCGAAGCCGATCCACGATTC }\end{array}$ & & & \\
\hline 16BIP & $\begin{array}{l}\text { TGAAGAGTGGAGGCATTGGC } \\
\text { CGCACGGGTTACAGTCATTGT }\end{array}$ & & & \\
\hline $\begin{array}{l}16 \text { F-Loop } \\
16 \text { B-Loop }\end{array}$ & $\begin{array}{l}\text { GACGTATTGAATCCTCACG } \\
\text { CTATAGCGATTACAGTTAT }\end{array}$ & & & \\
\hline
\end{tabular}


Table 2. Bacterial strains of known identity assayed with Rhodococcus fascians-specific primers $\mathrm{p} 450$ and fas and the "universal" 16S rRNA polymerase chain reaction (PCR) primers ${ }^{\mathrm{a}}$

\begin{tabular}{|c|c|c|c|c|}
\hline Species & Strain ID & $\mathrm{p}^{250^{b}}$ & fas & $16 S$ \\
\hline Acidovorax avenae & C-138 & - & - & + \\
\hline Agrobacterium radiobacter & A29/93 & - & - & + \\
\hline A. radiobacter & AS1/95 & - & - & + \\
\hline A. radiobacter & $\mathrm{C} 1 / 81$ & - & - & + \\
\hline A. radiobacter & K84 & - & - & + \\
\hline A. radiobacter & PM1 & - & - & + \\
\hline A. rhizogenes & 15834 & - & - & + \\
\hline A. rhizogenes & A1/83 & - & - & + \\
\hline A. rhizogenes & A4 & - & - & + \\
\hline A. tumefaciens & $\mathrm{BI} 2 / 95$ & - & - & + \\
\hline A. tumefaciens & B68/95 & - & - & + \\
\hline A. tumefaciens & C58 & - & - & + \\
\hline A. tumefaciens & D106/87 & - & - & + \\
\hline A. tumefaciens & M53/79 & - & - & + \\
\hline A. tumefaciens & RR5 & - & - & + \\
\hline A. tumefaciens & T219/94 & - & - & + \\
\hline A. vitis & $05-2$ & - & - & + \\
\hline A. vitis & BR26/95 & - & - & + \\
\hline A. vitis & CG42 & - & - & + \\
\hline Burkholderia cepacia & PCA4 & - & - & + \\
\hline $\begin{array}{l}\text { Clavibacter michiganensis } \\
\text { subsp. sepidonicus }\end{array}$ & 378 & - & - & + \\
\hline $\begin{array}{l}\text { Curtobacterium } \\
\text { flaccumfaciens }\end{array}$ & NE 21 & - & - & + \\
\hline Erwinia rhapontici & $05-72$ & - & - & + \\
\hline E. rhapontici & 26420 & - & - & + \\
\hline Microbacterium testaceum & $06-872$ & - & - & + \\
\hline Pantoea agglomerans & 26-SR-6-2 & - & - & + \\
\hline P. vagans & C9-15 & - & - & + \\
\hline Pectobacterium carotovorum & $73-22$ & - & - & + \\
\hline $\begin{array}{l}P . \text { carotovorum subsp. } \\
\text { carotovorum }\end{array}$ & CC301 & - & - & + \\
\hline P. chrysanthemi & B27 & - & - & + \\
\hline Pseudomonas agrici & ATCC25941 & - & - & + \\
\hline P. cichorii & $4-211$ & - & - & + \\
\hline P. fluorescens & A506 & - & - & + \\
\hline P. maltophilia & RM145 & - & - & + \\
\hline P. marginalis & PM7 & - & - & + \\
\hline P. putida & A12 & - & - & + \\
\hline P. savastanoi & $10-1076$ & - & - & + \\
\hline P. syringae pv. phaseolicola & HB-3 & - & - & + \\
\hline P. syringae pv. syringae & $11 \mathrm{E}$ & - & - & + \\
\hline Rhizobium japonicum & 3164 & - & - & + \\
\hline R. japonicum & ATCC 11927 & - & - & + \\
\hline R. leguminosarum & 175G11 & - & - & + \\
\hline R. meliloti & ATCC 10312 & - & - & + \\
\hline R. trifolii & ATCC10328 & - & - & + \\
\hline R. trifolii & $\mathrm{T} 1$ & - & - & + \\
\hline Rhodococcus coprophilus & $06-620-1 \mathrm{R}$ & - & - & + \\
\hline R. fascians & D-188 & + & + & + \\
\hline R. fascians & NCPPB 1488 & + & + & + \\
\hline R. fascians & NCPPB 1488c & $-^{\mathrm{c}}$ & - & + \\
\hline R. fascians & NCPPB $2551 \mathrm{t} 2$ & + & + & + \\
\hline R. fascians & NCPPB 469 & + & + & + \\
\hline R. fascians & PD302 & - & - & + \\
\hline R. fascians & VT141t1 & - & - & + \\
\hline Xanthomonas campestris & B498 & - & - & + \\
\hline$X$. campestris & 426 & - & - & + \\
\hline X. campestris & ATCC 33913 & - & - & + \\
\hline$X$. hortorum pv. carotae & M801 & - & - & + \\
\hline$X$. translucens & 148 & - & - & + \\
\hline
\end{tabular}

${ }^{a}$ Bacterial isolates used here were part of the Oregon State University Botany and Plant Pathology bacterial culture collection. Primers for the 16S rRNA are from Pei et al. (23).

${ }^{\mathrm{b}}$ A minus sign indicates assay results were negative; a plus sign signifies assay results were positive.

${ }^{\mathrm{c}}$ Isolate NCPPB $1488 \mathrm{c}$ has been cured of the plasmid carrying the genes for pathogenicity. The remaining isolates of $R$. fascians which are listed as negative with the p450 and fas primers did not produce symptoms when inoculated to Pisum sativum in the course of this study. bright fluorescence when exposed to UV-illumination indicated a positive LAMP reaction. LAMP amplification products were also electrophoresed in a $1.5 \%$ agarose gel and visualized by ethidiumbromide staining.

To confirm that primer set p16 amplified the target DNA, products were separated in a $0.8 \%$ agarose gel, and the smallest band ( 200 bp) was excised, frozen, thawed, and the DNA extracted by centrifugation through glass wool. This LAMP product was then cloned into pCR 4-TOPO Vector (TOPO TA Cloning Kit for sequencing, Invitrogen), isolated from the transformed Escherichia coli DH5 $\alpha$ (QIAprep Spin Miniprep Kit, Qiagen), and sequenced (Center for Genome Research and Biocomputing, Oregon State University).

To confirm the specificity of the p16 primers in the absence of additional loop primers, the LAMP assay was performed using DNA extracts from 13 reference strains of plant-associated bacteria and seven reference strains of pathogenic or nonpathogenic $R$. fascians. Template DNA was prepared by heat lysis of a single colony. Sensitivity of the LAMP primers was determined using 10fold serial dilutions of strain A44a. Cell concentrations were confirmed by plating aliquots of the suspensions as described previously. Bacterial DNA was extracted by heat lysis using $100 \mu \mathrm{l}$ of each dilution added to $200 \mu \mathrm{l} \mathrm{MGW}$. Each dilution, in 100- $\mu$ l aliquots, was also spiked into tissue samples of either petunia or evening primrose, and total DNA extracted (FastDNA SPIN kit). The LAMP assay used $3 \mu \mathrm{l}$ of the resulting extracts as template in the reaction.

The optimal $\mathrm{MgSO}_{4}$ concentration and time for precipitate formation were determined using a turbidimeter (Loopamp realtime turbidimeter, LA-320c, SA Scientific) for $70 \mathrm{~min}$, set at $64^{\circ} \mathrm{C}$. Sensitivity of primer set p16 was also tested using the optional primers 16 F-loop and 16 B-loop (Table 1) at a final concentration of $0.2 \mu \mathrm{M}$. To determine if excess nontarget DNA can interfere with detection of $R$. fascians, increasing numbers of $A$. tumefaciens cells (1.5-, 15-, and 150-fold more than $R$. fascians) were mixed with cells of strain A44a (final CFU/reaction: $1 \times 10^{4}$ ) prior to heat lysis and assaying with LAMP. A. tumefaciens is a ubiquitous soilborne bacterium that is often associated with plants affected by $R$. fascians (24). The comparative sensitivity of the PCR and LAMP primers was determined in parallel assays. Serial 10-fold dilutions of strain A44a were prepared and DNA of each dilution extracted using heat lysis; cell concentration was confirmed as described above. Additionally, bacterial DNA was spiked into tissue samples of petunia or evening primrose and total DNA extracted as previously described. Three microliters of the resulting extracts were used in LAMP and PCR reactions. The ability of the p16 LAMP primers, without the optional B-loop and F-loop primers, to detect $R$. fascians in naturally infected plant material was tested using 88 samples submitted to the Plant Clinic for diagnosis during the years 2002 to 2011 (Table 4). These same samples were also assayed using the p450 and fas PCR primers. Pathogenicity was determined for 44 of the 67 bacteria recovered from the samples by inoculation to indicator hosts.

\section{Results}

Identification of new bacterial strains. Of 33 bacterial strains which produced leafy galls when inoculated to indicator plants, the Biolog system failed to provide identification for 23. Of the 10 remaining, one was identified as Corynebacterium nitrilophilus, two as $R$. coprophilus, and one as Rhodococcus sp. Only six were correctly identified as $R$. fascians (Table 3 ).

Pathogenicity testing. All sweet pea seedlings inoculated with pathogenic $R$. fascians showed distorted growth and multiple shoots 4 weeks postinoculation. Garden pea cultivars inoculated with pathogenic strains were symptomatic, and only one-third the size of the water controls. Plants of both sweet and garden peas inoculated with nonpathogenic $R$. fascians looked similar to the noninoculated controls, which were normal. Pathogenic $R$. fascians strains inoculated to evening primrose 'Siskiyou' produced shoot proliferation and leafy galls beginning 2 weeks after inoculation 
Table 3. Results of plant tissue extracts and bacterial strains assayed for Rhodococcus fascians using the p450 and fas polymerase chain reaction (PCR) primers ${ }^{\mathrm{a}}$

\begin{tabular}{|c|c|c|c|c|c|c|c|c|c|}
\hline \multirow[b]{2}{*}{ Plant } & \multirow[b]{2}{*}{ Cultivar } & \multirow[b]{2}{*}{ Sample } & \multirow{2}{*}{$\begin{array}{c}\text { State of } \\
\text { origin }\end{array}$} & \multicolumn{2}{|c|}{$\begin{array}{l}\text { Plant tissue } \\
\text { assayed }\end{array}$} & \multicolumn{2}{|c|}{$\begin{array}{c}\text { Bacteria } \\
\text { assayed }\end{array}$} & \multirow{2}{*}{$\begin{array}{l}\text { Patho- } \\
\text { genicity }\end{array}$} & \multirow[b]{2}{*}{ Biolog identification } \\
\hline & & & & p450 & fas & p450 & fas & & \\
\hline Acanthus mollis & & $05-2223-1$ & MI & & & + & + & + & Rhodococcus fascians \\
\hline A. spinosus & & $07-1748$ & MI & - & - & & & & No bacteria recovered \\
\hline A. spinosus & & 07-1936 & MI & - & - & & & & No ID ${ }^{b}$ \\
\hline Acer japonicum & & 06-1083 & $\mathrm{OR}$ & - & - & & & & No bacteria recovered \\
\hline Achillea millefolium & Paprika & $08-584$ & MN & - & - & - & - & & No ID \\
\hline Agastache cana & Sonoran Sunset & $06-1459$ & IA & - & - & & & & No bacteria recovered \\
\hline Agave geminiflora & Spaghetti Strap & $08-1804$ & MN & - & - & & & & No bacteria recovered \\
\hline Ajuga reptans & Chocolate Chip & $07-124$ & IA & _- & - & _- & - & & No ID \\
\hline Anthemis tinctoria & Sauce Hollandaise & $06-1460$ & IA & - & - & - & - & & No ID \\
\hline Argyranthemum sp. & & $06-1789$ & $\mathrm{CA}$ & - & - & & & & R. coprophilus \\
\hline Aruncus aethusifolius & & $08-580$ & MN & + & + & + & + & & No ID \\
\hline Aruncus $\times$ & Misty Lace & $08-1862$ & MI & + & + & & & & No ID \\
\hline Aster amellus & Violet Queen & A73a & PA & & & + & + & + & R. fascians \\
\hline A. chemosis & Woods Pink & $04-516$ & FL & & & - & - & - & No ID \\
\hline A. dumosus & Red Alert & $06-1472$ & IA & - & - & & & & No bacteria recovered \\
\hline A. lateriflorus & Lady in Black & 06-1132 & IA & - & - & & & & No bacteria recovered \\
\hline $\begin{array}{l}\text { Boltonia asteroides var. } \\
\text { latisquama }\end{array}$ & Nana & 06-1058 & IA & - & - & - & - & & No ID \\
\hline Brassica oleracea & Botrytis group & $08-1732$ & OR & - & - & - & - & & No ID \\
\hline Buddleia davadii & Nanho Blue & $06-1466$ & IA & - & - & & & & No bacteria recovered \\
\hline Campanula persicifolia & Blue & $07-488$ & IA & - & - & - & - & & No ID \\
\hline C. punctata & Plum Wine & $08-601$ & OR & + & + & + & + & + & No ID \\
\hline Campanula sp. & & $06-156-3$ & MI & + & + & + & + & + & No ID \\
\hline Campanula sp. & & $06-156-3 b$ & MI & & & + & + & + & No ID \\
\hline Campanula sp. & & $06-1885$ & NY & - & - & & & & No bacteria recovered \\
\hline Campanula $\times$ & Sarastro & $02-815$ & MI & & & + & + & + & $\begin{array}{l}\text { Corynebacterium } \\
\text { nitrilophilus }\end{array}$ \\
\hline Chionanthus virginiana & & $08-1481$ & OR & - & - & & & & \\
\hline Cleome hassleriana & & $07-2059$ & $\mathrm{CA}$ & - & - & & & & No bacteria recovered \\
\hline C. hassleriana & & $07-2060$ & $\mathrm{CA}$ & - & - & & & & No bacteria recovered \\
\hline Coreopsis sp. & & $08-443$ & MN & - & - & & & & \\
\hline Coreopsis verticillata & Zagreb & $08-579$ & MN & - & - & + & + & + & No ID \\
\hline C. verticillata & Moonbeam & $08-583$ & MN & - & - & & & & No bacteria recovered \\
\hline C. verticillata & Crème Brulée & $08-857$ & OR & - & - & & & & No bacteria recovered \\
\hline C. verticillata & Rosea & $06-872$ & $\mathrm{OH}$ & - & - & - & - & & $\begin{array}{l}\text { Microbacterium } \\
\text { testaceum }\end{array}$ \\
\hline Cuphea sp. & & $08-543$ & $\mathrm{CA}$ & - & - & & & & No bacteria recovered \\
\hline Delosperma cooperi & & $07-2085$ & WA & - & - & & & & No bacteria recovered \\
\hline Dianthus caryophyllus & & $07-1243$ & $\mathrm{CA}$ & + & + & + & + & & No ID \\
\hline D. gratianopolitanus & Firewitch Raspberry & $08-581$ & MN & - & - & & & & No bacteria recovered \\
\hline Dianthus sp. & & $07-214$ & $\mathrm{CA}$ & - & - & - & - & & No ID \\
\hline Dianthus $\times$ & Firestar & $06-1462$ & IA & - & - & & & & No bacteria recovered \\
\hline Dianthus $\times$ & Strawberry Sorbet & $06-1906$ & WA & - & - & & & & No bacteria recovered \\
\hline Echinacea purpurea & & $07-1839-1 \mathrm{a}$ & OR & & & - & - & & No ID \\
\hline E. purpurea & Little Magnus & $08-1756$ & WA & - & - & + & + & & No ID \\
\hline Erodium reichardii & & $08-259$ & $\mathrm{CA}$ & - & - & + & + & + & R. coprophilus \\
\hline E. reichardii & & $08-788$ & $\mathrm{CA}$ & - & - & - & - & - & Rhodococcus sp. \\
\hline Euonymus japonica & & $08-237$ & $\mathrm{CA}$ & - & - & & & & No bacteria recovered \\
\hline Euonymus sp. & & $06-1475$ & IA & - & - & & & & No bacteria recovered \\
\hline Fuchsia $\times$ & Indian Maid & $05-2256-b-3$ & OR & & & + & + & + & No ID \\
\hline Gaillardia grandiflora & Fanfare & $07-178$ & IA & - & - & - & - & & $\begin{array}{l}\text { Pseudomonas } \\
\text { fluorescens }\end{array}$ \\
\hline Gaura lindheimeri & Siskiyou Pink & $06-1463$ & IA & - & - & & & & No bacteria recovered \\
\hline $\begin{array}{l}\text { Geranium sanguineum } \\
\text { var. striatum }\end{array}$ & & $06-2169$ & WA & - & - & & & & $\begin{array}{l}\text { Agrobacterium } \\
\text { tumefaciens }\end{array}$ \\
\hline Heliopsis helianthoides & Loraine Sunshine & $07-655$ & WA & + & + & + & + & & R. fascians \\
\hline H. helianthoides & Loraine Sunshine & $\mathrm{A} 3 \mathrm{~b}$ & MI & & & + & + & + & $R$. fascians \\
\hline Herniaria glabra & Seafoam & $07-1747$ & MI & + & + & & & & R. fascians \\
\hline Heuchera sanguinea & Snow Angel & $07-339$ & WA & - & - & & & & No bacteria recovered \\
\hline Heuchera sp. & & $07-1895$ & IL & - & - & & & & No bacteria recovered \\
\hline Heuchera $\times$ & Princess Anastasia & $06-234-2 a$ & MI & - & - & - & - & - & No ID \\
\hline Hosta albomarginata & Gold Standard & $07-1734$ & MI & _- & - & & & & No bacteria recovered \\
\hline Hosta sp. & & $08-811-1-1 \mathrm{a}$ & MI & + & + & + & + & + & No ID \\
\hline Hosta $\times$ & Blue Umbrellas & $05-339-1$ & MI & & & + & + & + & No ID \\
\hline
\end{tabular}

a Plant samples were submitted to the OSU Plant Clinic for diagnosis. The bacteria tested were isolated from the plants submitted. Selected isolates were also assayed for pathogenicity on either Pisum sativum or Oenothera speciosa as described in the text. Where bacteria were isolated, identity was attempted using the substrate utilization assay marketed by Biolog (Hayward, CA). A blank in a column indicates the assay was not performed; a plus sign signifies a positive assay; and a minus sign signifies the assay results were negative.

b No identity was obtained with the Biolog system according to the criteria set by the manufacturer. 
Table 3. (continued from previous page)

\begin{tabular}{|c|c|c|c|c|c|c|c|c|c|}
\hline \multirow[b]{2}{*}{$\underline{\text { Plant }}$} & \multirow[b]{2}{*}{ Cultivar } & \multirow[b]{2}{*}{ Sample } & \multirow{2}{*}{$\begin{array}{c}\text { State of } \\
\text { origin }\end{array}$} & \multicolumn{2}{|c|}{$\begin{array}{c}\text { Plant tissue } \\
\text { assayed }\end{array}$} & \multicolumn{2}{|c|}{$\begin{array}{c}\text { Bacteria } \\
\text { assayed }\end{array}$} & \multirow{2}{*}{$\begin{array}{c}\text { Patho- } \\
\text { genicity }\end{array}$} & \multirow[b]{2}{*}{ Biolog identification } \\
\hline & & & & p450 & fas & p450 & fas & & \\
\hline Hosta $\times$ & Blue Umbrellas & 08-1801 & MN & - & - & & & & No bacteria recovered \\
\hline Hosta $\times$ & Carnival & $05-340-1$ & MI & & & + & + & + & No ID \\
\hline Hosta $\times$ & Carnival & $05-340-2$ & MI & & & + & + & + & No ID \\
\hline Hosta $\times$ & Dress Blues & $06-411-3$ & MI & & & - & - & & A. tumefaciens \\
\hline Hosta $\times$ & Elegans & $08-105$ & SC & - & - & & & & No bacteria recovered \\
\hline Hosta $\times$ & Fragrant Blue & $08-1860$ & MI & - & - & & & & No bacteria recovered \\
\hline Hosta $\times$ & Fragrant Blue & $08-1861$ & MI & + & + & + & + & & No ID \\
\hline Hosta $\times$ & Hadspen Blue & $08-235$ & MI & - & - & & & & No bacteria recovered \\
\hline Hosta $\times$ & Praying Hands & $07-1606$ & MI & + & + & & & & Rhodococcus sp. \\
\hline Hosta $\times$ & Praying Hands & 08-1802 & MN & - & - & & & & No bacteria recovered \\
\hline Hosta $\times$ & Sugar and Spice & $08-1803$ & MN & - & - & & & & No bacteria recovered \\
\hline Isolepis cernиа & & 06-1134 & IA & - & - & & & & No bacteria recovered \\
\hline Lamium maculatum & Beacon Silver & $08-578$ & $\mathrm{MN}$ & + & + & - & + & + & No ID \\
\hline L. maculatum & White Nancy & $06-1470$ & IA & - & - & & & & No bacteria recovered \\
\hline L. maculatum & White Nancy & $08-577$ & $\mathrm{MN}$ & - & - & + & + & - & No ID \\
\hline Lavandula angustifolia & Melissa Lilac & $06-2193$ & WA & - & - & & & & No bacteria recovered \\
\hline L. angustifolia & Violet Intrigue & $05-561$ & WA & & & - & - & - & \\
\hline Lavatera $\times$ clementii & Barnsley & 06-1059 & IA & - & - & - & - & & $\begin{array}{l}\text { Sphingobacterium } \\
\text { thalpophilum }\end{array}$ \\
\hline $\begin{array}{l}\text { Leucanthemum } \times \\
\text { superbum }\end{array}$ & Becky & $06-468-2-2$ & MI & & & + & + & + & No ID \\
\hline $\begin{array}{l}\text { Leucanthemum } \times \\
\text { superbum }\end{array}$ & Becky & 06-1968 & MI & - & + & & & & No bacteria recovered \\
\hline $\begin{array}{l}\text { Leucantheтит } \times \\
\text { superbum }\end{array}$ & Becky & 06-1969 & MI & - & + & & & & No bacteria recovered \\
\hline $\begin{array}{l}\text { Leucanthemum } \times \\
\text { superbum }\end{array}$ & Becky & $07-260$ & MN & + & + & + & + & & R. fascians \\
\hline $\begin{array}{l}\text { Leucanthemum } \times \\
\text { superbum }\end{array}$ & Becky & $08-368$ & OR & - & - & - & - & & No ID \\
\hline $\begin{array}{l}\text { Leucanthemum } \times \\
\text { superbum }\end{array}$ & Becky & $\mathrm{A} 22 \mathrm{~b}$ & WA & & & - & & - & No ID \\
\hline $\begin{array}{l}\text { Leucanthemum } \times \\
\text { superbum }\end{array}$ & Becky & A78 & PA & & & + & + & + & No ID \\
\hline $\begin{array}{l}\text { Leucanthemum } \times \\
\text { superbum }\end{array}$ & Esther Read & $06-325-1-1$ & WA & & & + & + & + & No ID \\
\hline $\begin{array}{l}\text { Leucanthemum } \times \\
\text { superbum }\end{array}$ & Gold Rush & $08-87$ & WA & + & + & & & + & R. fascians \\
\hline $\begin{array}{l}\text { Leucanthemuт } \times \\
\text { superbum }\end{array}$ & Gold Rush & $08-1863$ & MI & - & - & + & + & & R. fascians \\
\hline $\begin{array}{l}\text { Leucantheтит } \times \\
\text { superbum }\end{array}$ & Snow Cap & $06-467-1$ & MI & & & + & + & + & No ID \\
\hline Lilium sp. & & $07-68$ & WA & + & + & + & + & & \\
\hline Lilium sp. & & $07-69$ & WA & + & + & - & + & & \\
\hline Lilium sp. & & $07-168$ & WA & + & + & & & & No bacteria recovered \\
\hline Lilium sp. & & $07-169$ & WA & + & + & & & & No bacteria recovered \\
\hline Lilium sp. & & $07-170$ & WA & - & + & & & & No bacteria recovered \\
\hline Lilium sp. & & $07-171$ & WA & - & + & & & & No bacteria recovered \\
\hline Lilium sp. & & $07-1390$ & WA & + & + & & & & \\
\hline Lilium sp. & & $07-1596$ & WA & + & + & & & & No ID \\
\hline Lilium sp. & & $07-1597$ & WA & + & + & & & & No ID \\
\hline Lilium sp. & & $07-1598$ & WA & + & + & & & & No ID \\
\hline Lilium sp. & & $07-2032$ & WA & - & - & & & & No bacteria recovered \\
\hline Lilium sp. & & $07-2033$ & WA & - & - & & & & No bacteria recovered \\
\hline Lilium sp. & & $07-2034$ & WA & - & + & & & & No bacteria recovered \\
\hline Lilium sp. & & $07-2035$ & WA & - & - & & & & No bacteria recovered \\
\hline Lilium sp. & & $07-2036$ & WA & + & + & & & & No bacteria recovered \\
\hline Lobelia sp. & & $08-96$ & $\mathrm{CA}$ & - & - & & & & No bacteria recovered \\
\hline Lysimachia clethroides & & $06-1465$ & IA & - & - & & & & No bacteria recovered \\
\hline Malus domestica & & $07-340$ & OR & & & - & - & - & Agrobacterium sp. \\
\hline Monarda didyma & Petite Delight & $08-424$ & IN & - & - & - & - & & \\
\hline Nemesia sp. & & $06-621-1$ & $\mathrm{CA}$ & + & & + & + & + & No ID \\
\hline Oenothera speciosa & Siskiyou & $08-89$ & WA & + & + & & & + & \\
\hline Osteospermum sp. & & $08-77$ & $\mathrm{NH}$ & - & - & & & & \\
\hline Pelargonium sp. & & $07-273$ & $\mathrm{KS}$ & - & - & & & & No bacteria recovered \\
\hline Pelargonium sp. & & $07-1662$ & FL & - & - & & & & No bacteria recovered \\
\hline Pelargonium sp. & & $07-1788$ & IL & - & - & & & & No bacteria recovered \\
\hline Pentas lanceolata & Cranberry Punch & $06-761$ & MD & - & - & - & - & - & A. tumefaciens \\
\hline P. lanceolata & & 08-1920 & $\mathrm{CA}$ & - & - & & & & No bacteria recovered \\
\hline \multirow[t]{2}{*}{ Petunia $\times$ hybrida } & & $07-1027$ & $\mathrm{CA}$ & & & - & - & - & \\
\hline & & & & & & & & & (continued on next page) \\
\hline
\end{tabular}


Table 3. (continued from previous page)

\begin{tabular}{|c|c|c|c|c|c|c|c|c|c|}
\hline \multirow[b]{2}{*}{ Plant } & \multirow[b]{2}{*}{ Cultivar } & \multirow[b]{2}{*}{ Sample } & \multirow{2}{*}{$\begin{array}{c}\text { State of } \\
\text { origin }\end{array}$} & \multicolumn{2}{|c|}{$\begin{array}{c}\text { Plant tissue } \\
\text { assayed }\end{array}$} & \multicolumn{2}{|c|}{$\begin{array}{l}\text { Bacteria } \\
\text { assayed }\end{array}$} & \multirow{2}{*}{$\begin{array}{l}\text { Patho- } \\
\text { genicity }\end{array}$} & \multirow[b]{2}{*}{ Biolog identification } \\
\hline & & & & p450 & fas & p450 & fas & & \\
\hline Petunia $\times$ hybrida & & $08-437$ & $\mathrm{CA}$ & + & + & + & + & + & No ID \\
\hline Phlox paniculata & Bright Eyes & 07-208 & MI & - & - & & & & No bacteria recovered \\
\hline P. paniculata & Pink Flame & $06-871$ & WA & - & - & + & + & & No ID \\
\hline Phlox $\times$ & Miss Candy & $06-1471$ & IA & - & - & & & & No bacteria recovered \\
\hline Physocarpus opulifolius & & $08-858$ & OR & - & - & + & + & + & Rhodococcus sp. \\
\hline Rhododendron sp. & & $07-177$ & WA & - & - & & & & No bacteria recovered \\
\hline Rhododendron $\times$ & Aglo & $08-1930$ & OR & - & - & & & & No bacteria recovered \\
\hline Rhododendron $\times$ & Golden Lights & 08-1946 & OR & - & - & - & - & & $R$. fascians \\
\hline Rosa sp. & Yellow Brick Road & $07-76$ & OR & - & - & - & - & & A. rhizogenes \\
\hline Rosa sp. & Morden Centennial & $07-258$ & $\mathrm{MN}$ & - & - & & & & Agrobacterium sp. \\
\hline Rosa sp. & Prairie Sunrise & $07-259$ & MN & - & - & & & & Agrobacterium sp. \\
\hline Rosa sp. & Yellow Brick Road & $07-2062$ & OR & - & - & & & & No bacteria recovered \\
\hline Rosa sp. & Sweet Fragrance & $07-2112$ & OR & - & - & & & & No bacteria recovered \\
\hline Rosa sp. & Paint the Town & $07-2112$ & OR & - & - & & & & No bacteria recovered \\
\hline Rudbeckia sp. & & $07-213$ & $\mathrm{CA}$ & - & - & & & & No bacteria recovered \\
\hline Rudbeckia sp. & & $07-1242$ & NY & - & - & & & & No bacteria recovered \\
\hline Salix purpurea & Nana & $07-257 a$ & MT & - & - & - & - & & A. tumefaciens \\
\hline Salvia $\times$ sylvestris & Blauhügel & $06-1473$ & IA & - & - & & & & No bacteria recovered \\
\hline Salvia $\times$ sylvestris & Mainacht & $06-1474$ & IA & - & - & & & & $R$. fascians \\
\hline Scabiosa comumbaria & Butterfly & $08-582$ & $\mathrm{MN}$ & - & - & - & - & - & R. coprophilus \\
\hline Scabiosa sp. & & $08-444$ & $\mathrm{MN}$ & - & - & - & - & - & No ID \\
\hline Sedum ewersii & Ewersii & $06-1478$ & IA & - & - & & & & No bacteria recovered \\
\hline $\begin{array}{l}\text { S. kamtschaticum var. } \\
\text { variegatum }\end{array}$ & & $06-1467$ & IA & - & - & & & & No bacteria recovered \\
\hline S. spurium & Dragon's Blood & $06-1468$ & IA & - & - & & & & No bacteria recovered \\
\hline Sequoia sempervirens & & $08-236$ & $\mathrm{CA}$ & - & - & & & & No bacteria recovered \\
\hline Sorbaria sorbifolia & Sem & $08-445$ & $\mathrm{MN}$ & + & + & + & + & + & No ID \\
\hline S. sorbifolia & Sem & $08-446-3 a$ & $\mathrm{MN}$ & + & + & + & + & + & No ID \\
\hline S. sorbifolia & Sem & $08-585$ & $\mathrm{MN}$ & + & + & + & + & + & R. coprophilus \\
\hline Verbascum $\times$ & Jackie & 06-1891 & MI & - & - & & & & No bacteria recovered \\
\hline Verbascum $\times$ & Jackie in Pink & 06-1893 & MI & - & - & & & & No bacteria recovered \\
\hline Verbascum $\times$ & Plum Smokey & $07-1607$ & MI & - & - & & & & No bacteria recovered \\
\hline Verbena $\times$ & Shauna Ann & $05-2224-3 a$ & MI & & & + & + & + & No ID \\
\hline Veronica $\times$ & Goodness Grows & $06-469-2-1$ & MI & & & + & + & + & \\
\hline Veronica spicata & Blue Charm & $06-1476$ & IA & - & - & & & & No bacteria recovered \\
\hline$V$. spicata & Icicle White & $06-1477$ & IA & + & + & + & + & & $R$. fascians \\
\hline V. spicata & Minuet & A44a & $\mathrm{PA}$ & & & + & + & + & No ID \\
\hline V. spicata & Red Fox & $06-873$ & $\mathrm{OH}$ & - & - & + & + & & R. fascians \\
\hline V. spicata & Royal Candles & $05-2081$ & MI & & & + & + & + & \\
\hline V. spicata & Royal Candles & $06-418-1 b$ & MI & + & & + & + & + & No ID \\
\hline V. spicata & Royal Candles & $06-1100$ & MI & + & + & & & & No bacteria recovered \\
\hline V. spicata & Royal Candles & 06-1970 & MI & - & + & & & & No bacteria recovered \\
\hline V. spicata & Royal Candles & 06-1971 & MI & - & - & & & & No bacteria recovered \\
\hline V. spicata & Royal Candles & $07-577$ & WA & - & + & + & + & + & R. fascians \\
\hline V. spicata & Sunny Border Blue & $05-2254-5$ & WA & & & + & + & + & R. fascians \\
\hline V. spicata & Sunny Border Blue & $06-470-1-2$ & MI & & & - & - & - & No ID \\
\hline V. spicata & Sunny Border Blue & $06-1133$ & IA & + & + & & & & No bacteria recovered \\
\hline V. spicata & Tickled Pink & $06-516-1$ & FL & & & - & - & - & Curtobacterium citreum \\
\hline V. spicata & Waterperry Blue & $06-1461$ & IA & - & - & & & & No bacteria recovered \\
\hline Vinca minor & & 06-1479 & IA & - & - & & & & No bacteria recovered \\
\hline Vinca sp. & & $07-1787$ & IL & - & - & & & & No bacteria recovered \\
\hline Viola $\times$ & Purple Showers & $02-816 c$ & MI & & & + & + & + & No ID \\
\hline Viola $\times$ & Purple Showers & $02-816 \mathrm{~d}$ & MI & & & - & - & - & Microbacterium terregens \\
\hline Vitis vinifera & Pinot Noir & $07-1340$ & OR & - & - & & & & Pseudomonas sp. \\
\hline
\end{tabular}

(Fig. 1). As evening primrose was easier to inoculate than pea, and because symptoms were more consistent with those of naturally infected nursery plants, this plant species replaced garden pea in pathogenicity assays after 2004.

PCR detection of $\boldsymbol{R}$. fascians. PCR products of the correct size were obtained only for the four pathogenic reference strains of $R$. fascians (Table 2). No amplicon was obtained for one nonpathogenic $R$. fascians strain, which had been cured of the plasmid containing the virulence genes (NCPPB1488c), nor for isolates PD302 and VT141t1 (Table 2), which did not incite disease in garden pea. When petunia leaf tissue extracts were spiked with quantified cell suspensions of $R$. fascians strain A44a, the lower limit of detection was approximately 1,000 CFU/PCR reaction for both the p450 and fas primer sets (data not shown). The p450 primers were used suc- cessfully to detect $R$. fascians from all 34 inoculated plants (plant wash assay; data not shown). When frozen DNA extracts from most inoculated plants were later tested with the fas primers, all plants that had been inoculated with $R$. fascians $(n=22)$ produced a product of the expected size.

All 169 samples sent to our lab for diagnosis of either A. tumefaciens or $R$. fascians from 2002 to 2008 were assayed for $R$. fascians using PCR with the $\mathrm{p} 450$ and fas primer pairs (with DNA from plant tissue extracts or plant washes, the latter of which was for samples preceding number 08-89), culture-based detection, or both (Table 3). Considering the plant tissue extracts only, there was agreement between the p450 and fas primer sets for 132 of 139 (95\%) plants (Table 3). Seven samples produced a PCR product with the fas primers only (i.e., were fas-positive). Six of the seven 
Table 4. Results of plant tissues and bacterial cultures assayed for pathogenic Rhodococcus fascians with loop-mediated isothermal amplification (LAMP) and polymerase chain reaction $(\mathrm{PCR})^{\mathrm{a}}$

\begin{tabular}{|c|c|c|c|c|c|c|c|c|}
\hline \multirow[b]{2}{*}{ Plant name } & \multirow[b]{2}{*}{ Cultivar } & \multirow{2}{*}{$\begin{array}{l}\text { Sample } \\
\text { number }\end{array}$} & \multirow{2}{*}{$\begin{array}{l}\text { State or country } \\
\text { of origin }\end{array}$} & \multirow{2}{*}{$\begin{array}{l}\text { Patho- } \\
\text { genicity }\end{array}$} & \multirow{2}{*}{$\begin{array}{l}\text { LAMP } \\
\text { results }^{b}\end{array}$} & \multicolumn{2}{|c|}{ PCR results } & \multirow{2}{*}{$\begin{array}{l}\text { Material } \\
\text { assayed }\end{array}$} \\
\hline & & & & & & fas & p450 & \\
\hline Acanthus mollis & & $05-2223-1$ & MI & + & + & + & + & Bacteria \\
\hline Achillea millefolium & Paprika & $08-584$ & $\mathrm{MN}$ & NT & - & - & - & Bacteria \\
\hline Angelonia $\times$ & Actors White & $09-2347-1$ & MI & NT & + & + & + & Bacteria \\
\hline Angelonia $\times$ & Actors White & $09-2347-2$ & MI & NT & + & + & + & Bacteria \\
\hline Aster amellus & Violet Queen & $\mathrm{A} 73 \mathrm{a}$ & PA & + & + & + & + & Bacteria \\
\hline Aster dumosus & Woods Pink & $04-516$ & FL & - & - & - & - & Bacteria \\
\hline Sutera cordata & $\begin{array}{l}\text { Scopia Great Pink } \\
\text { Ring }\end{array}$ & $10-1523$ & UT & NT & + & + & + & Tissue \\
\hline $\begin{array}{l}\text { Brassica oleracea var. } \\
\text { botrytis }\end{array}$ & & 08-1732 & OR & NT & - & - & - & Bacteria \\
\hline Campanula punctata & Plum Wine & $08-601$ & OR & + & + & + & + & Bacteria \\
\hline Campanula sp. & & $06-156-3 b$ & MI & + & + & + & + & Bacteria \\
\hline Campanula $\times$ & Sarastro & $02-815$ & MI & + & + & + & + & Bacteria \\
\hline Cleome sp. & & $10-2022$ & $\mathrm{CA}$ & NT & - & - & - & Tissue \\
\hline Coreopsis verticillata & Zagreb & $08-579$ & $\mathrm{MN}$ & + & + & + & + & Bacteria \\
\hline Coreopsis $\times$ & Jive & $10-212-2$ & MI & NT & - & - & - & Tissue \\
\hline Dianthus $\times$ & Cinnamon Red Hot & $10-1976$ & $\mathrm{CA}$ & NT & - & - & - & Tissue \\
\hline Dianthus $\times$ & Cinnamon Red Hot & 10-1976-1-1-ai & $\mathrm{CA}$ & NT & - & - & - & Bacteria \\
\hline Dianthus $\times$ & Cinnamon Red Hot & 10-1976-1-1-aii & $\mathrm{CA}$ & NT & - & - & - & Bacteria \\
\hline Dianthus $\times$ & Cinnamon Red Hot & $10-1976-1-1 b$ & $\mathrm{CA}$ & NT & - & - & - & Bacteria \\
\hline Dianthus $\times$ & Cinnamon Red Hot & $10-1976-2-2 a$ & $\mathrm{CA}$ & NT & - & - & - & Bacteria \\
\hline Echinacea purpurea & & $07-1839-1 \mathrm{a}$ & OR & NT & - & - & - & Bacteria \\
\hline Echinacea $\times$ & After Midnight & 09-1953-1 & WA & NT & - & - & - & Bacteria \\
\hline Echinacea $\times$ & After Midnight & 09-1953-2 & WA & NT & - & - & - & Bacteria \\
\hline Echinacea $\times$ & Gum Drop & $10-999-1-1$ & OR & NT & - & + & - & Tissue \\
\hline Erodium reichardii & & $08-259$ & $\mathrm{CA}$ & + & + & + & + & Bacteria \\
\hline E. reichardii & & $08-788$ & $\mathrm{CA}$ & - & - & - & - & Bacteria \\
\hline Fuchsia sp. & & 10-121a-1 & OR & NT & + & + & + & Tissue \\
\hline Fuchsia sp. & & $10-121 a-2$ & OR & NT & + & + & + & Tissue \\
\hline Fuchsia sp. & & $10-121 a-1-3$ & OR & NT & - & + & + & Bacteria \\
\hline Fuchsia sp. & & $10-121 a-1-4$ & OR & NT & + & + & + & Bacteria \\
\hline Fuchsia $\times$ & Indian Maid & $05-2256 b-3$ & OR & + & + & + & + & Bacteria \\
\hline Heliopsis helianthoides & Loraine Sunshine & $\mathrm{A} 3 \mathrm{~b}$ & MI & + & + & + & + & Bacteria \\
\hline Heuchera sp. & & $11-42$ & MA & NT & - & - & - & Tissue \\
\hline Heuchera sp. & & $11-43$ & MA & NT & - & - & - & Tissue \\
\hline Heuchera sp. & & $11-44$ & MA & NT & - & - & - & Tissue \\
\hline Heuchera sp. & & $11-45$ & MA & NT & - & - & - & Tissue \\
\hline Heuchera sp. & & $11-46$ & MA & NT & - & - & - & Tissue \\
\hline Heuchera $\times$ & Caramel & $11-205$ & $\mathrm{OH}$ & NT & - & - & - & Tissue \\
\hline Heuchera $\times$ & Dark Secret & $11-204$ & $\mathrm{OH}$ & NT & - & - & - & Tissue \\
\hline Heuchera $\times$ & Princes Anastasia & $06-234-2 \mathrm{a}$ & MI & - & - & - & - & Bacteria \\
\hline Hibiscus rosa-sinensis & Carolina Breeze & $10-718-2-1$ & FL & NT & - & - & - & Tissue \\
\hline H. rosa-sinensis & Carolina Breeze & $10-718-2-2$ & FL & NT & - & - & - & Tissue \\
\hline Hosta sp. & & $08-811$ & MI & + & + & + & + & Bacteria \\
\hline Hosta $\times$ & Blue Umbrellas & $05-339-1$ & MI & + & + & + & + & Bacteria \\
\hline Hosta $\times$ & Carnival & $05-340-2$ & MI & + & + & + & + & Bacteria \\
\hline Hosta $\times$ & Dress Blues & $06-411-3$ & MI & $+^{c}$ & - & - & - & Bacteria \\
\hline Iberis semipervins & Purity & $\mathrm{A} 24 \mathrm{c}$ & WA & - & - & - & - & Bacteria \\
\hline Iberis $\times$ & Absolutely Amethyst & $10-1629$ & $\mathrm{CA}$ & NT & + & + & + & Tissue \\
\hline Ipomoea $\times$ & Green Yellow & $10-710-1$ & $\mathrm{CA}$ & NT & + & + & + & Tissue \\
\hline Iротоеа $\times$ & Green Yellow & $10-710-2$ & $\mathrm{CA}$ & NT & + & + & + & Tissue \\
\hline Iротоеа $\times$ & Green Yellow & $10-931-1-1$ & $\mathrm{CA}$ & NT & - & - & - & Bacteria \\
\hline Ipomoea $\times$ & Green Yellow & $10-931-2-1-2 b$ & $\mathrm{CA}$ & NT & + & + & + & Bacteria \\
\hline Lavandula angustifolia & Violet Intrigue & $05-561$ & WA & - & - & - & - & Bacteria \\
\hline L. angustifolia & Violet Intrigue & $06-561-1$ & WA & - & - & NT & - & Bacteria \\
\hline Leucanthemum sp. & & $11-176$ & $\mathrm{CA}$ & NT & - & - & - & Tissue \\
\hline $\begin{array}{l}\text { Leucanthemum } \times \\
\text { superbum }\end{array}$ & Becky & $06-468-2-2$ & MI & + & + & + & + & Bacteria \\
\hline $\begin{array}{l}\text { Leucanthemum } \times \\
\text { superbum }\end{array}$ & Becky & 09-2323-1 & NY & NT & - & - & - & Bacteria \\
\hline $\begin{array}{l}\text { Leucanthemum } \times \\
\text { superbum }\end{array}$ & Becky & $09-2323-2$ & NY & NT & - & - & - & Bacteria \\
\hline
\end{tabular}

a Plant samples were submitted to the Oregon State University Plant Clinic for diagnosis. Bacterial cultures (except the reference isolates) were obtained from infected plants submitted. Plus signs indicate the sample was positive and minus signs indicate the sample was negative in the assay. NT means the sample was not assayed for the test indicated.

b Results are the summary of duplicate assays.

c This sample was infected with a pathogenic strain of Agrobacterium tumefaciens.

${ }^{\mathrm{d}}$ Isolates NCPPB $1488 \mathrm{c}$ and D-188c have been cured of the plasmid carrying the genes for pathogenicity. The remaining isolates which are listed as negative for pathogenicity did not produce symptoms when inoculated to Pisum sativum in the course of this study. 
Table 4. (continued from previous page)

\begin{tabular}{|c|c|c|c|c|c|c|c|c|}
\hline \multirow[b]{2}{*}{ Plant name } & \multirow[b]{2}{*}{ Cultivar } & \multirow{2}{*}{$\begin{array}{l}\text { Sample } \\
\text { number }\end{array}$} & \multirow{2}{*}{$\begin{array}{l}\text { State or country } \\
\text { of origin }\end{array}$} & \multirow{2}{*}{$\begin{array}{l}\text { Patho- } \\
\text { genicity }\end{array}$} & \multirow{2}{*}{$\begin{array}{l}\text { LAMP } \\
\text { results }^{b}\end{array}$} & \multicolumn{2}{|c|}{ PCR results } & \multirow{2}{*}{$\begin{array}{l}\text { Material } \\
\text { assayed }\end{array}$} \\
\hline & & & & & & fas & p450 & \\
\hline $\begin{array}{l}\text { Leucantheтит } \times \\
\text { superbum }\end{array}$ & Becky & $\mathrm{A} 22 \mathrm{~b}$ & WA & - & - & - & - & Bacteria \\
\hline $\begin{array}{l}\text { Leucanthemum } \times \\
\text { superbum }\end{array}$ & Becky & A78 & PA & + & + & + & + & Bacteria \\
\hline $\begin{array}{l}\text { Leucantheтит } \times \\
\text { superbum }\end{array}$ & Broadway Lights & $10-1795-1-3-2 \mathrm{a}$ & CA & NT & + & + & + & Tissue \\
\hline $\begin{array}{l}\text { Leucanthemum } \times \\
\text { superbum }\end{array}$ & Broadway Lights & $10-1795-1-3-2 b$ & CA & NT & + & + & + & Tissue \\
\hline $\begin{array}{l}\text { Leucanthemum } \times \\
\text { superbum }\end{array}$ & Esther Read & $06-325-1-1$ & WA & + & + & + & + & Bacteria \\
\hline $\begin{array}{l}\text { Leucantheтит } \times \\
\text { superbum }\end{array}$ & Snow Cap & $06-467-1$ & MI & + & + & + & + & Bacteria \\
\hline $\begin{array}{l}\text { Leucanthemum } \times \\
\text { superbum }\end{array}$ & Snow Cap & $10-135-1$ & VA & NT & + & + & + & Tissue \\
\hline $\begin{array}{l}\text { Leucanthemum } \times \\
\text { superbum }\end{array}$ & Sunny Side Up & $10-138-1$ & VA & NT & + & + & + & Tissue \\
\hline Nemesia sp. & & $06-621-1$ & $\mathrm{CA}$ & + & + & + & + & Bacteria \\
\hline Nemesia $\times$ & Natalie & A25f & WA & + & + & + & + & Bacteria \\
\hline Oenothera speciosa & Siskiyou & $05-22552 b-1$ & WA & + & + & + & + & Bacteria \\
\hline O. speciosa & Siskiyou & $08-89-1$ & OR & + & + & + & + & Bacteria \\
\hline Osteospermum $\times$ & Lemon Symphony & $10-242$ & CA & NT & - & - & - & Tissue \\
\hline Osteospermum $\times$ & Orange Spark & $10-243$ & $\mathrm{CA}$ & NT & - & - & - & Tissue \\
\hline Pelargonium peltatum & & $10-121 b$ & OR & NT & + & + & + & Tissue \\
\hline P. peltatum & & $10-121 b-1$ & OR & NT & + & + & + & Bacteria \\
\hline Petunia $\times$ hybrida & & $08-437$ & CA & + & + & + & + & Bacteria \\
\hline Petunia $\times$ hybrida & Surfina Baby Red & $10-1077-1$ & UT & NT & - & - & - & Tissue \\
\hline Petunia $\times$ hybrida & Surfina Baby Red & $10-1077-2$ & UT & NT & - & - & - & Tissue \\
\hline Petunia $\times$ hybrida & Vista Fuchsia & $10-142-1$ & $\mathrm{CA}$ & NT & + & + & + & Tissue \\
\hline Petunia $\times$ hybrida & Vista Fuchsia & $10-142-2$ & $\mathrm{CA}$ & NT & + & + & + & Tissue \\
\hline Phlox paniculata & Flame Lilac & $10-743-1-1$ & PA & NT & $+/-$ & - & - & Bacteria \\
\hline P. paniculata & Flame Lilac & $10-743-2$ & PA & NT & + & + & + & Tissue \\
\hline P. paniculata & Flame Lilac & $10-743-2-1$ & PA & NT & + & + & + & Tissue \\
\hline Phlox sp & . & 09-1941-1 & $\mathrm{OH}$ & NT & - & - & - & Bacteria \\
\hline Phlox sp. & & $09-1941-2$ & $\mathrm{OH}$ & NT & - & - & - & Bacteria \\
\hline Physocarpus opulifolius & & $08-858$ & $\mathrm{MN}$ & + & + & + & + & Bacteria \\
\hline Salix purpurea & Nana & $07-257 \mathrm{a}$ & MT & - & - & - & - & Bacteria \\
\hline Sorbaria sorbifolia & Sem & $08-446-3 a$ & $\mathrm{MN}$ & + & + & + & + & Bacteria \\
\hline Torenia $\times$ & Summer Wave Blue & $11-207$ & $\mathrm{CA}$ & NT & - & - & - & Tissue \\
\hline Verbena $\times$ & Goodness Grows & $06-469-2-1$ & MI & + & + & + & + & Bacteria \\
\hline Verbena $\times$ & Shauna Ann & $05-2224-3 a$ & MI & + & + & + & + & Bacteria \\
\hline Verbena $\times$ & Temari Cherry Red & $10-1079-1$ & UT & NT & - & - & - & Tissue \\
\hline Verbena $\times$ & Temari Cherry Red & $10-1082-1$ & UT & NT & - & - & - & Tissue \\
\hline Veronica sp. & & $10-815-1-1$ & UT & NT & + & + & + & Bacteria \\
\hline Veronica sp. & & $10-815-1-2$ & UT & NT & + & + & + & Tissue \\
\hline Veronica sp. & & $10-815-2-1$ & UT & NT & + & + & + & Tissue \\
\hline Veronica sp. & & $10-815-2-2$ & UT & NT & + & + & + & Tissue \\
\hline Veronica spicata & Royal Candles & A76 & MI & + & + & + & + & Bacteria \\
\hline V. spicata & Royal Candles & $05-2081$ & MI & + & + & + & + & Bacteria \\
\hline V. spicata & Royal Candles & $06-418-1 \mathrm{a}$ & MI & + & + & + & + & Bacteria \\
\hline V. spicata & Royal Candles & $06-418-1 b$ & MI & + & + & + & + & Bacteria \\
\hline V. spicata & Royal Candles & $10-134-1$ & VA & NT & - & + & - & Tissue \\
\hline V. spicata & Royal Candles & $10-420-1 \mathrm{a}$ & WA & NT & + & + & + & Tissue \\
\hline V. spicata & Royal Candles & $10-420-1 b$ & WA & NT & + & + & + & Tissue \\
\hline V. spicata & Royal Candles & $10-420-2 \mathrm{a}$ & WA & NT & + & + & + & Tissue \\
\hline V. spicata & Royal Candles & $10-420-2 b$ & WA & NT & + & + & + & Tissue \\
\hline V. spicata & Royal Candles & $10-1468-1$ & $\mathrm{MN}$ & NT & - & - & - & Tissue \\
\hline V. spicata & Royal Candles & $10-1468-2$ & $\mathrm{MN}$ & NT & + & + & + & Tissue \\
\hline V. spicata & Sunny Border Blue & $06-470-1-2$ & MI & - & - & - & - & Bacteria \\
\hline V. spicata & Sunny Border Blue & $06-470-3$ & MI & + & $+1-$ & + & + & Bacteria \\
\hline V. spicata & Sunny Border Blue & $05-2254-5$ & WA & + & + & + & + & Bacteria \\
\hline V. spicata & Sunny Border Blue & $10-139-1$ & VA & NT & + & + & + & Tissue \\
\hline V. spicata & Tickled Pink & $10-1509$ & PA & NT & + & + & + & Tissue \\
\hline Veronica $\times$ & Eveline & $10-137-1$ & VA & NT & + & + & + & Tissue \\
\hline Veronica $\times$ & Eveline & $10-137-1-3$ & VA & NT & + & + & + & Bacteria \\
\hline Veronica $\times$ & Minuet & A44a & PA & + & + & + & + & Bacteria \\
\hline Viola $\times$ & Purple Showers & $02-816 c$ & MI & + & + & + & + & Bacteria \\
\hline Viola $\times$ & Purple Showers & $02-816 \mathrm{~d}$ & MI & - & - & - & - & Bacteria \\
\hline
\end{tabular}


Table 4. (continued from previous page)

\begin{tabular}{|c|c|c|c|c|c|c|c|c|}
\hline \multirow[b]{2}{*}{ Plant name } & \multirow[b]{2}{*}{ Cultivar } & \multirow{2}{*}{$\begin{array}{l}\text { Sample } \\
\text { number }\end{array}$} & \multirow{2}{*}{$\begin{array}{c}\text { State or country } \\
\text { of origin }\end{array}$} & \multirow{2}{*}{$\begin{array}{l}\text { Patho- } \\
\text { genicity }\end{array}$} & \multirow{2}{*}{$\begin{array}{l}\text { LAMP } \\
\text { results }^{b}\end{array}$} & \multicolumn{2}{|c|}{ PCR results } & \multirow{2}{*}{$\begin{array}{l}\text { Material } \\
\text { assayed }\end{array}$} \\
\hline & & & & & & fas & p450 & \\
\hline \multicolumn{9}{|c|}{ Reference isolates of $R$. fascians } \\
\hline \multicolumn{2}{|c|}{$\begin{array}{l}\text { Fragaria chiloensis var. } \\
\text { ananassa }\end{array}$} & NCPPB 469 & UK & + & + & + & + & Bacteria \\
\hline \multicolumn{2}{|l|}{ Lathyrus odoratus } & NCPPB $1488 \mathrm{c}$ & UK & $-^{\mathrm{d}}$ & - & - & - & Bacteria \\
\hline \multicolumn{2}{|l|}{ L. odoratus } & NCPPB 2551 & UK & + & + & + & + & Bacteria \\
\hline \multirow{2}{*}{\multicolumn{2}{|c|}{$\begin{array}{ll}\text { Lilium speciosum } & \text { Rubrum } \\
\text { Euphorbia } & \end{array}$}} & VT141t1 & Belgium & - & - & - & - & Bacteria \\
\hline & & PD302 & Netherlands & - & - & - & - & Bacteria \\
\hline \multicolumn{2}{|l|}{$\begin{array}{l}\text { Chrysanthemum } \\
\text { morifolium }\end{array}$} & D-188 & UK & + & + & + & + & Bacteria \\
\hline \multicolumn{2}{|l|}{ C. morifolium } & D-188c & UK & - & - & - & - & Bacteria \\
\hline
\end{tabular}

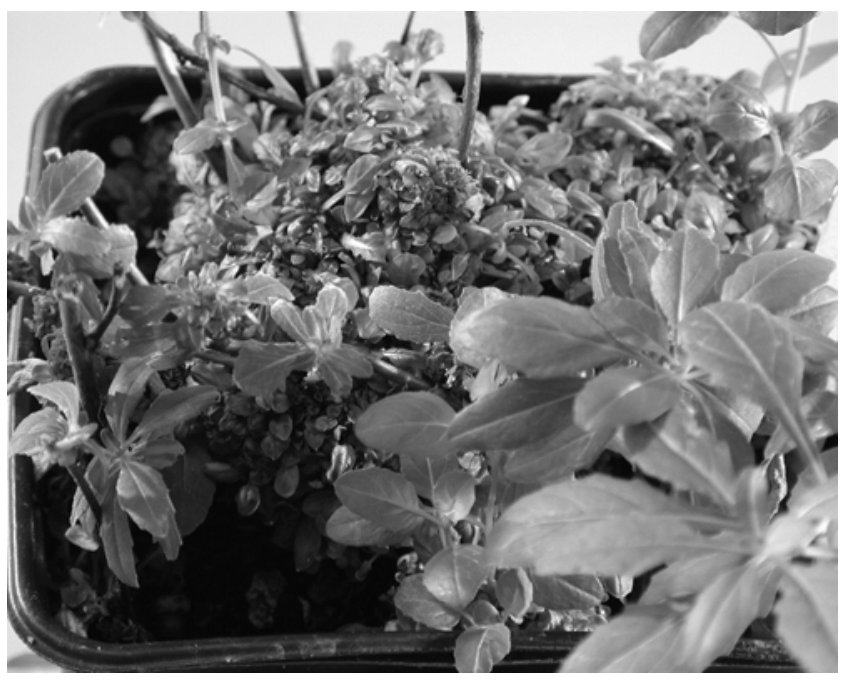

Fig. 1. Symptoms of Rhodococcus fascians on an inoculated Oenothera speciosa plant. Shown is a massive leafy gall in the center of the pot, with normal leaves on an unaffected stem at the lower right.

fas-positive samples were received in poor condition or had been treated with bactericides, and thus were not suitable for culturebased detection. One of the seven fas-positive samples (from Veronica spicata) was truly infected with pathogenic $R$. fascians, as determined by host inoculation, and hence was a false negative according to the $\mathrm{p} 450$ primers. However, there were no instances, when assaying plant tissue extracts, in which the p450 primers gave positive results and the fas primers gave negative results.

For identification of 75 bacterial strains isolated from 169 samples, results using the two primer pairs were consistent for 73 (97\%) bacterial strains (Table 3). Two bacterial strains were positively identified as $R$. fascians, based on fas primers, but were p450-negative. Pathogenicity of the bacteria isolated from one of the fas-positive, p450-negative samples was not tested because the bacteria did not survive storage, but bacteria isolated from the other sample produced symptoms when inoculated to evening primrose, suggesting a false-negative with the $\mathrm{p} 450$ primers. Based on pathogenicity tests of 46 of the 75 bacterial isolates recovered, the p450 and fas primers correctly discriminated between 31 pathogenic and 12 nonpathogenic (43 total) strains. For the remaining three strains, there were the following inconsistencies between the primers and the pathogenicity tests: one fas-positive, p450positive strain was nonpathogenic; one fas-negative, $\mathrm{p} 450$-negative strain was pathogenic; and one fas-positive, p450-negative strain was pathogenic. Finally, of the 169 plant samples assayed for $R$. fascians, there were eight from which extracts of bacteria recovered from the plants reacted with both the p450 and fas primers, but plant tissue extracts did not.

LAMP detection of $\boldsymbol{R}$. fascians. From 20 sets of FIP/BIP and F3/B3 primer pairs, we selected one (p16) for further evaluation. The smallest product band (arrowhead, Fig. 2B) amplified using p16 was gel-purified, cloned, and sequenced, and found to be the
A

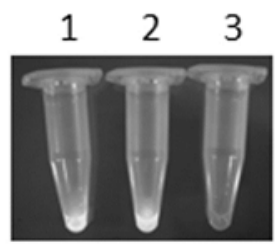

B Lane: 1234

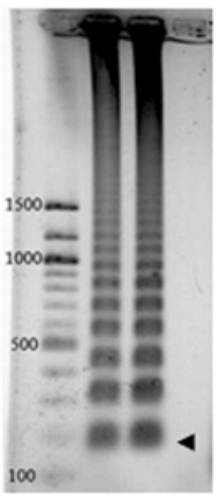

Fig. 2. Loop-mediated isothermal amplification (LAMP) of Rhodococcus fascians DNA. A, PicoGreen detection of positive LAMP reactions. LAMP was performed with primer set $p 16$ without the optional loop primers using the standard condition (Materials and Methods). A DNA ( 100 ng) extract of strain A44a was added to reactions 1 and 2. No DNA was added to reaction 3. An aliquot $(5 \mu \mathrm{l})$ of each completed reaction was added to $1 \mu \mathrm{l}$ PicoGreen, and fluorescence was excited using an ultraviolet-illuminator. B, Gel-electrophoresis of LAMP products amplified using primer set p16. LAMP was performed as described for A. Aliquots $(10 \mu \mathrm{l})$ of completed reactions were run on a $1.5 \%$ agarose gel. Lane 1 is a 100 -bp DNA ladder; lanes 2 and 3, A44a DNA as template; and lane 4, no DNA (water control). Arrowhead: example of LAMP-product purified for sequencing.

expected DNA sequence. No amplicon was formed when set p16 was tested against DNA from 13 plant-associated bacteria, including other hyperplasia-inducing species. Tested were Acidovorax avenae, Agrobacterium radiobacter (two strains), A. rhizogenes, $A$. tumefaciens, A. vitis, Bacillus uniflagellatus, Curtobacterium flaccumfaciens, Erwinia amylovora, Pectobacterium carotovorum, Pseudomonas maltophila, $P$. savastanoi, and $P$. syringae. The p16 primers correctly discriminated between three pathogenic strains (NCPPB 469, NCPPB 2551, and D-188) and four nonpathogenic strains (NCPPB 1488c, VT141t1, PD302, and D-188c) of $R$. fascians. A precipitate formed in positive $R$. fascians LAMP (LAMPpositive) reactions, but only as a pellet after brief centrifugation. To enhance detection, we added PicoGreen to the reaction product, which produces a yellow color under daylight and fluoresces under UV light in a LAMP-positive reaction, and is orange and nonfluorescent in a LAMP-negative reaction (Fig. 2A). There was correlation between precipitate formation and fluorescence with PicoGreen in 148 of 158 reactions of known $R$. fascians cell concentrations (data not shown). In 10 reactions, there had been fluorescence but no precipitate, suggesting the dye was more sensitive at detecting amplification. Optimal time for precipitate formation was evaluated using a real-time turbidity meter for 70 min. Turbidity was dependent on $\mathrm{MgSO}_{4}$ concentration and reached a maximum at $6 \mathrm{mM} \mathrm{MgSO}_{4}$ (data not shown), the concentration used in our standard conditions. No product or precipitate formed when $\mathrm{MgSO}_{4}$ was at or below $3 \mathrm{mM}$, and by 50 min the LAMP reaction was at an exponential phase of amplification, saturating at $70 \mathrm{~min}$. 



Fig. 3. Loop-mediated isothermal amplification (LAMP) sensitivity with and without loop-primers. LAMP reactions using primer set p16 were measured in real-time using a turbidity meter. DNA extracted from varying amounts of Rhodococcus fascians (strain A44a) colony-forming units was added to each reaction as follows: a, 5 $\times 10^{4} ; b, 5 \times 10^{3} ; c, 5 \times 10^{2} ; \mathrm{d}, 5 \times 10^{1} ; \mathrm{e}$, no DNA. A, LAMP in absence of loop primers. B, LAMP in presence of loop primers. LAMP reactions included 16 F-loop and $16 \mathrm{~B}$-loop primers. Data is representative of four independent experiments.

Real-time turbidity was monitored using set p16 and extracts of known $R$. fascians cell concentrations. The detection limit for the p16 primers was $5 \times 10^{3} \mathrm{CFU}$ per $30 \mu \mathrm{l}$ LAMP reaction (Fig. 3A). Addition of F-loop and B-loop primers accelerated the LAMP reaction and shifted the exponential phase back to between 35 and $60 \mathrm{~min}$. The loop primers increased sensitivity to $5 \times 10^{2}$ CFU/reaction (Fig. 3B). There was a gradual increase in turbidity in the absence of DNA template (Fig. 3A and B), and no LAMP product was detectable with PicoGreen or gel electrophoresis. Table 5 shows the detection limits of set p16 in the absence and presence of additional loop primers, which increased sensitivity of the assay in five of six cell concentrations to levels below that required for disease development (21). However, the frequency of false-positive reactions was unacceptably high (33\%, Table 5). No false positives were generated in the absence of the loop primers, hence they were not used in our LAMP assays.

We found neither plant extracts nor extraneous bacterial DNA inhibited LAMP. $R$. fascians extracts with 1.5-, 15-, or 150-fold excess A. tumefaciens DNA still produced a LAMP-positive reaction, and we were consistently able to detect varying amounts of $R$. fascians DNA ( $\geq 1 \times 10^{3} \mathrm{CFU} / 30 \mu$ reaction) added to petunia or evening primrose leaf tissue. When using $R$. fascians DNA combined with petunia tissue, there was no inhibition of the PCR reaction. In contrast, PCR of $R$. fascians DNA and evening primrose tissue was inhibited, and dilution was necessary to visualize product formation. The detection limit of both assays was comparable. LAMP detected $R$. fascians at $\geq 1 \times 10^{3}$ CFU/30 $\mu$ l reaction in $80 \%$ of the reactions (Table 5), whereas p450 and fas detected $R$. fascians at $\geq 1 \times 10^{3} \mathrm{CFU} / 30 \mu \mathrm{l}$ reaction for two of three experiments and $\geq 1 \times 10^{4} \mathrm{CFU} / 30 \mu \mathrm{l}$ for the third.

LAMP and PCR were used to assay 49 symptomatic and asymptomatic plant tissue extracts and 67 bacterial strains isolated from 84 plant samples gathered over 10 years from 13 states (Table 4). The results of both assays agreed for 113 of 116 (97\%) plant samples and bacterial strains, with the exceptions noted below. Of
Table 5. Sensitivity of the Rhodococcus fascians-specific loop-mediated isothermal amplification (LAMP) assay with and without additional loop primers

\begin{tabular}{|c|c|c|c|}
\hline \multicolumn{2}{|c|}{ Loop primers $^{a}$} & \multicolumn{2}{|c|}{ No loop primers } \\
\hline $\mathrm{CFU}^{\mathrm{b}}$ & Frequencyc $^{\mathrm{c}}(\%)$ & CFU & Frequency $(\%)$ \\
\hline $1-5 \times 10^{5}$ & $8 / 8(100)$ & $1-5 \times 10^{5}$ & $2 / 2(100)$ \\
\hline $1-5 \times 10^{4}$ & $15 / 15(100)$ & $1-5 \times 10^{4}$ & $8 / 9(89)$ \\
\hline $1-5 \times 10^{3}$ & $15 / 16(94)$ & $1-5 \times 10^{3}$ & $8 / 10(80)$ \\
\hline $1-5 \times 10^{2}$ & $6 / 16(38)$ & $1-5 \times 10^{2}$ & $1 / 10(10)$ \\
\hline $1-5 \times 10^{1}$ & $4 / 16(25)$ & $1-5 \times 10^{1}$ & $0 / 10(0)$ \\
\hline $1-5$ & $1 / 8(12)$ & $1-5$ & $0 / 2(0)$ \\
\hline $0.1-0.5$ & $0 / 4(0)$ & $0.1-0.5$ & Not tested \\
\hline False-positives ${ }^{\mathrm{d}}$ & $4 / 12(33)$ & False-positives & $0 / 12(0)$ \\
\hline False-negatives ${ }^{\mathrm{e}}$ & $1 / 39(2)$ & False-negatives & $3 / 21(14)$ \\
\hline
\end{tabular}

${ }^{a}$ LAMP reactions included 16FIP/16BIP and 16F3/16B3 primers, and either no additional loop primers or the $16 \mathrm{~F}$-loop/16 B-loop primers. Reactions were incubated for $70 \mathrm{~min}$ at $65^{\circ} \mathrm{C}$.

b $\mathrm{CFU}=$ colony-forming units.

${ }^{\mathrm{c}}$ Frequency $=$ ratio of positive LAMP reactions (numerator) to the total number of reactions (denominator).

${ }^{\mathrm{d}}$ False positives occurred when fluorescence was observed in the water controls (no DNA template) when PicoGreen was added to the reaction vessel at the end of the incubation period.

e Negative reactions occurred when there was no fluorescence with the addition of PicoGreen to the reaction vessels at the end of the incubation period when the template was $\geq 1 \times 10^{3} \mathrm{CFU}$ reference strain of $R$. fascians.

28 tissue extracts from plants with leafy galls, 26 were PCR- and LAMP-positive. Two samples were LAMP- and p450-negative, but fas-positive (Table 4). Since the samples were of symptomatic plants, these results suggest the fas-positive was correct. Of 21 plant samples with either crown gall or no symptoms, all were PCR- and LAMP-negative. The p16 primers were used on DNA extracts of 67 bacterial strains recovered from the plant samples. Twenty-five of 26 strains isolated from asymptomatic plants were LAMP-negative. One strain produced mixed results between the two LAMP replicates and were p450- and fas-negative, suggesting it was not pathogenic $R$. fascians. Of 41 bacterial strains isolated from plants with leafy galls, 40 were LAMP-positive. One strain was LAMP-negative and p450- and fas-positive, suggesting a false negative with LAMP. Finally, LAMP results differed between the replicates for one strain which was pathogenic and p450- and faspositive (Table 4). Usually when there was a discrepancy between replicate LAMP sample results, a repeat of the assay produced agreement between the replicates. Thirty-three of the 67 bacterial strains were pathogenic upon inoculation, and all were LAMPpositive, whereas all of the 11 nonpathogenic strains were LAMPnegative.

\section{Discussion}

Both PCR and LAMP assays were effective in amplifying DNA from pathogenic strains of $R$. fascians in vitro and in planta. The PCR primers were successful in identifying $R$. fascians from 169 plant samples, representing more than 70 plants species, originating from 17 states, and gathered over a period of 7 years. Both PCR primers accurately and specifically amplified only pathogenic reference cultures of $R$. fascians, and not 51 other plant-associated bacteria in vitro. PCR primers specific to virulence genes of $R$. fascians were previously published $(21,27)$, but our work is unique in developing a rapid, reliable diagnostic tool for pathogenic $R$. fascians based on DNA-based detection of the virulence genes, and validated on plant samples from the field. The LAMP primers were successful in identifying $R$. fascians from 116 bacterial or plant extracts from naturally infected plant samples, representing 34 plant species, originating from 13 states, and gathered over a period of 10 years. The LAMP assay amplified only pathogenic reference cultures of $R$. fascians, and did not amplify 13 other plant-associated bacteria in vitro. There was excellent agreement between the LAMP p16 primers and the p450 and fas PCR pri- 
mers, and between these DNA-based methods and the pathogenicity tests. Culture-based detection is the "gold standard" for detection of $R$. fascians. Given the importance of knowing the true status of propagation material (infected or not), isolation is easily done, albeit time-consuming. However, the PCR or LAMP assays described here not only detect $R$. fascians, but are specific to pathogenic strains, which is an improvement on culture-based detection. The DNA-based detection assays described here were developed with the typical equipment of either a molecular diagnostic laboratory (PCR assay) or a well-equipped large commercial nursery (LAMP assay). The simplicity and sensitivity of LAMP assay, in particular, opens up new means of ensuring biosecurity.

The ability to reliably detect pathogenic $R$. fascians in planta using PCR has streamlined our ability to confirm a diagnosis in 1 day compared to the four or more weeks for culture-based detection or inoculation to indicator hosts. The LAMP assay has shortened diagnosis to only $2 \mathrm{~h}$. By adding loop primers (18) to our assay, we increased sensitivity, although with an unacceptably high level of false positives. The LAMP p16 primers (without the loop primers), as well as the PCR primers, had a lower detection limit of 1,000 CFU/30- $\mu$ l reaction. We assume that quantification of DNA amplified from the virulence genes is approximate, however, because the proportion of pathogenic $R$. fascians cells varies within a population (21). Nonetheless, as $2.5 \times 10^{4} \mathrm{CFU} / \mathrm{ml}$ is the minimal concentration of $R$. fascians required to stimulate symptoms in pea seedlings (21), it is possible that our PCR and LAMP methods have sufficient sensitivity to detect $R$. fascians in the very early stages of infection.

A turbidimeter was useful in optimizing our LAMP reaction, but is not essential for accurate $R$. fascians detection. The addition of PicoGreen eased visualization of the reaction result, as the magnesium pyrophosphate precipitation was at times difficult to evaluate. However, PicoGreen has some drawbacks. LAMP reaction products are extremely stable, and opening tubes to add product to PicoGreen may increase the risk of contamination of laboratory equipment with LAMP amplicons, thereby increasing the risk of false positives (33). As such, tubes of LAMP amplicons should be opened away from the sample extraction and reaction preparation areas.

The LAMP and PCR primers target different gene regions, which increases their utility as diagnostic tools. The PCR primers we developed are specific to plasmid-borne genes intimately involved with cytokinin production $(4,5,27,28)$, the primary means by which $R$. fascians causes plant disfigurement. We developed two primer sets rather than only one to increase diagnostic confidence in the case of nucleotide mutations that alter the primer binding site. Indeed, the p450 primers occasionally gave different results than the fas primers, the latter of which appear to be more accurate. The gene region targeted by the $\mathrm{p} 450$ primers may be more variable than the highly conserved fas $D$ gene.

The eight samples from which bacterial extracts were positive by PCR, but from which tissue extracts were negative, was likely due to the presence of PCR inhibitors in the plant cells. Our plant wash method was meant to minimize cell disruption, but it prolonged assay time and did not remove PCR inhibitors, so this method was replaced by direct tissue extracts. Supplementing PCR reactions with BSA, and/or diluting template DNA depending on the plant species, reduced inhibition sufficiently to allow product amplification. LAMP is less susceptible to PCR inhibitors $(8,22)$. Indeed, in our comparisons of PCR and LAMP using petunia and evening primrose tissues spiked with $R$. fascians DNA, we found that PCR, but not LAMP, was inhibited by compounds in evening primrose tissues. As this manuscript was in review, a real-time PCR protocol for detection of $R$. fascians was published (19), which may have potential, but requires validation with plant material, as direct tissue extracts do not always result in detection.

Although substrate-utilization assays for coryneform bacteria have been available and found accurate for medically important strains (2), this has not been the case for plant-pathogenic coryneforms. A commercial substrate utilization system (Biolog) gives inconsistent identification of $R$. fascians (6), and our findings of only six out of 31 accurate Biolog identifications support this observation. Harris-Baldwin and Gudmestad (6) used a supplemented database and found correct $R$. fascians identification for only $33 \%$ of samples. Individual $R$. fascians isolates may thus have greater flexibility in substrate utilization than is currently recognized, rendering nutritional requirements as identification criteria problematic.

\section{Acknowledgments}

This study was supported by grants from the Oregon Department of Agriculture and the USDA Floral and Nursery Crops Research Initiative. We thank K. Collins for creating the $\mathrm{p} 450$ primer pair, Paul Reeser for a critical reading of the manuscript, and Todd Temple for his valuable input throughout this project. We are indebted to the senior editor and two anonymous reviewers for their thoughtful and constructive comments.

\section{Literature Cited}

1. Altschul, S. F., Gish, W., Miller, W., Myers, E. W., and Limpan, D. J. 1990. Basic local alignment search tool. J. Mol. Biol. 215:403-410.

2. Bizet, C., Barreau, C., Harmant, C., Nowakowski, M., and Pietfroid, A. 1997. Identification of Rhodococcus, Gordonia and Dietzia species using carbon source utilization tests ("Biotype-100" strips). Res. Microbiol. 148:799-809.

3. Cornelis, K., Ritsema, T., Nijsse, J., Holsters, M., Goethals, K., and Jaziri, M. 2001. The plant pathogen Rhodococcus fascians colonizes the exterior and interior of the aerial parts of plants. Mol. Plant-Microbe Interact. 14:599-608.

4. Crespi, M., Messens, E., Caplan, A. B., Van Montagu, M., and Desomer, J. 1992. Fasciation induction by the phytopathogen Rhodococcus fascians depends upon a linear plasmid encoding a cytokinin synthase gene. EMBO J. 11:795-804.

5. Crespi, M., Vereecke, D., Temmerman, W., Van Montagu, M., and Desomer, J. 1994. The fas operon of Rhodococcus fascians encodes new genes required for efficient fasciation of host plants. J. Bacteriol. 176:2492-2501.

6. Harris-Baldwin, A., and Gudmestad, N. C. 1996. Identification of phytopathogenic coryneform bacteria using the Biolog automated microbial identification system. Plant Dis. 80:874-878.

7. Kado, C., and Heskett, M. G. 1970. Selective medium for isolation of Agrobacterium, Corynebacterium, Erwinia, Pseudomonas, and Xanthomonas. Phytopathology 60:969-976.

8. Kaneko, H., Kawana, T., Fukushima, E., and Suzutani, T. 2007. Tolerance of loop-mediated isothermal amplification to a culture medium and biological substances. J. Biochem. Biophys. Methods 70:499-501.

9. Kikuchi, T., Aikawa, T., Oeda, Y., Karim, N., and Kanzaki, N. 2009. A rapid and precise diagnostic method for detecting the pinewood nematode Bursaphelenchus xylophilus by loop-mediated isothermal amplification. Phytopathology 99:1365-1369.

10. Kubota, R., Vine, B. G., Alvarez, A. M., and Jenkins, D. M. 2008. Detection of Ralstonia solanacearum by loop-mediated isothermal amplification. Phytopathology 98:1045-1051.

11. Lacey, M. S. 1936. Studies in Bacteriosis XXII. Further studies on a bacterium causing fasciation of sweet peas. Ann. Appl. Biol. 23:743-751.

12. Lacey, M. S. 1939. Studies in Bacteriosis XXIV. Studies on a bacterium associated with leafy galls, fasciations and "cauliflower" disease of various plants. Part III. Further isolations, inoculation experiments and cultural studies. Ann. Appl. Biol. 26:262-278.

13. Lacey, M. S. 1955. The cytology and relationships of Corynebacterium fascians. Trans. Br. Mycol. Soc. 38:49-58.

14. Lelliott, R. A., and Stead, D. E. 1991. Methods for the Diagnosis of Bacterial Diseases of Plants. Wiley-Blackwell, London.

15. Maes, T., Vereecke, D., Ritsema, T., Cornelius, K., Thu, H. N. T., Van Montagu, M., Holsters, M., and Goethals, K. 2001. The att locus of Rhodococcus fascians strain D188 is essential for full virulence on tobacco through the production of an auto regulatory compound. Mol. Microbiol. 42:13-26.

16. Manes, C.-L. de O., Van Montagu, M., Prinsen, E., Goethals, K., and Holsters, M. 2001. De novo cortical cell division triggered by the phytopathogen Rhodococcus fascians in tobacco. Mol. Plant-Microbe Interact. 14:189194.

17. Miller, M. L., and Putnam, M. L. 2008. Pathogenicity testing of Agrobacterium tumefaciens and Rhodococcus fascians isolates on micropropagated plants. (Abstr.) Phytopathology 98:S106.

18. Nagamine, K., Hast, T., and Totomi, T. 2002. Accelerated reaction by loopmediated isothermal amplification using loop primers. Mol. Cell. Probes 16:223-229.

19. Nikolaeva, E. V., Kang, S., Olson, T. N., and Kim, S. H. 2012. Real-time PCR detection of Rhodococcus fascians and discovery of new plants associated with $R$. fascians in Pennsylvania. Online. Plant Health Progress doi:10.1094/PHP-2012-0227-02-RS

20. Nikolaeva, E. V., Park, S.-K., Kang, S., Olson, T. N., and Kim, S. H. 2007. Recurrence of bacterial fasciation on flowering potted plants in Pennsylvania. (Abstr.) Phytopathology 97:S84 
21. Nikolaeva, E. V., Park, S.-Y., Kang, S., Olson, T. N., and Kim, S. H. 2009. Ratios of cells with and without virulence genes in Rhodococcus fascians populations correlate with degrees of symptom development. Plant Dis. 93:499-506.

22. Notomi, T., Okayama, H., Masubuchi, H., Yonekawa, T., Watanabe, K., Amino, N., and Hase, T. 2000. Loop-mediated isothermal amplification of DNA. Nucleic Acids Res. 28: e63. doi: 10.1093/nar/28.12. e63

23. Pei, Z., Bini, E. J., Yang, L., Zhou, M., Francois, F., and Blaser, M. J. 2004. Bacterial biota in the human distal esophagus. PNAS 101:4250-4255.

24. Putnam, M. L., and Miller, M. L. 2007. Rhodococcus fascians in herbaceous perennials. Plant Dis. 91:1064-1076.

25. Rigano, L. A., Marano, M. R., Castagnaro, A. P., DoAmara, A. M., and Vojnov, A. A. 2010. Rapid and sensitive detection of citrus bacterial canker by loop-mediated isothermal amplification combined with simple visual evaluation methods. BMC Microbiol. 10:176. doi:10.1186/1471-2180-10-176

26. Smith, E. F. 1922. Fasciation and prolepsis due to crown gall. Phytopathology 12:265-270

27. Stange, R. R., Jeffares, D., Young, C., Scott, D. B., Eason, J. R., and Jameson, P. E. 1996. PCR amplification of the fas-1 gene for the detection of virulent strains of Rhodococcus fascians. Plant Pathol. 45:407-417.

28. Stes, E., Vandeputte, O. M., El Jaziri, M., Holsters, M., and Vereecke, D. 2011. A successful bacterial coup d'e'tat: How Rhodococcus fascians redi- rects plant development. Annu. Rev. Phytopathol. 49:69-86.

29. Temmerman, W., Vereecke, D., Dreesen, R., Van Montagu, M., Holsters, M., and Goethals, K. 2000. Leafy gall formation is controlled by fasR, an AraC-type regulatory gene in Rhodococcus fascians. J. Bacteriol. 182:58325840 .

30. Temple, T. N., and Johnson, K. B. 2011. Evaluation of loop-mediated isothermal amplification for rapid detection of Erwinia amylovora on pear and apple fruit flowers. Plant Dis. 95:423-430.

31. Temple, T. N., Stockwell, V. O., and Johnson, K. B. 2007. Development of a rapid detection method for Erwinia amylovora by loop-mediated isothermal amplification (LAMP). Acta Hortic. 793:497-503.

32. Tilford, P. E. 1936. Fasciation of sweet peas caused by Phytomonas fascians n. sp. J. Agric. Res. 53:383-394.

33. Tomlinson, J., and Boonham, N. 2008. Potential of LAMP for detection of plant pathogens. CAB Reviews: Perspectives in Agriculture, Veterinary Science, Nutrition and Natural Resources 3, 066:1-7.

34. Tomlinson, J. A., Dickinson, M., and Boonham, N. 2010. Detection of Botrytis cinerea by loop-mediated isothermal amplification. Lett. Appl. Microbiol. 51:650-657.

35. Ulrychová, M., and Petrů, E. 1983. Isolation of some strains of Coryne bacterium fascians (Tilford) Dowson in Czechoslovakia. Biol. Plantarum (Praha) 25:63-67. 